2010-07-08

\title{
Clinical Prediction in Group Psychotherapy
}

Christopher L. Chapman

Brigham Young University - Provo

Follow this and additional works at: https://scholarsarchive.byu.edu/etd

Part of the Psychology Commons

\section{BYU ScholarsArchive Citation}

Chapman, Christopher L., "Clinical Prediction in Group Psychotherapy" (2010). Theses and Dissertations. 2144.

https://scholarsarchive.byu.edu/etd/2144

This Dissertation is brought to you for free and open access by BYU ScholarsArchive. It has been accepted for inclusion in Theses and Dissertations by an authorized administrator of BYU ScholarsArchive. For more information, please contact scholarsarchive@byu.edu, ellen_amatangelo@byu.edu. 
Clinical Prediction in Group Psychotherapy

\author{
Christopher Chapman
}

\begin{abstract}
A dissertation submitted to the faculty of Brigham Young University in partial fulfillment of the requirements for the degree of

Doctor of Philosophy
\end{abstract}

Gary M. Burlingame Patrick Steffen Mark Beecher Sally H. Barlow John Okiishi

\author{
Department of Clinical Psychology \\ Brigham Young University
}

August 2010

Copyright (C) 2010 Christopher Chapman

All Rights Reserved 


\author{
ABSTRACT \\ Clinical Prediction in Group Psychotherapy \\ Christopher Chapman \\ Department of Clinical Psychology \\ Doctor of Philosophy
}

Prior research in individual therapy has provided evidence that therapists are poor predictors of client outcome without the aid of objective measures and often misjudge clients' perceptions of the therapeutic relationship. The focus of the current research was to conduct a similar study in a group setting. Therapists from a university counseling center and a state psychiatric hospital were recruited to test their accuracy in predicting client outcome, quality of therapeutic relationship and their own use of empirically supported group interventions. Results indicated that therapists are poor predictors of all three, providing support for the implementation of measure-based feedback systems to inform therapists about key information that may affect the effectiveness of group psychotherapy.

Keywords: group psychotherapy, clinical prediction, outcome, cohesion 


\section{ACKNOWLEDGEMENTS}

I would like to thank Gary Burlingame for his mentorship and investment in my work. Additionally, I would like to thank my dissertation committee for their willingness to work with me, their feedback, and their support. I would also like to thank my wife Laura for her many unpaid hours of editing and listening to my gripes. Also, many thanks to all of the students who worked hard with me on my research team to make this possible. 


\section{TABLE OF CONTENTS}

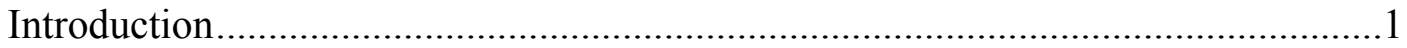

Literature Review.....................................................................................

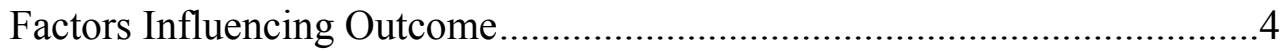

A New, Comprehensive Model of the Group Relationship ........................

Defining the Therapeutic Group Relationship: The Development of the

Group Questionnaire ............................................................ 10

Trends in Patient-Focused Research: A Response to "Evidence-Based

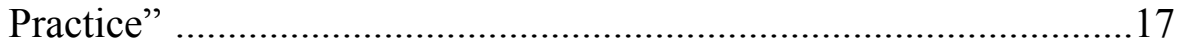

The 'Dose-Response’ Model in Tracking Therapy Outcomes .....................19

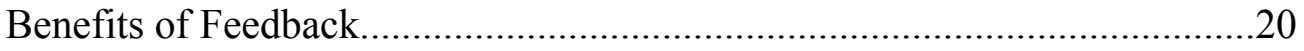

Clinical and Empirical Prediction Methods .............................................21

Can Therapists Accurately Predict Client Status and Outcome? ..................22

Providing Client Progress Feedback to Clinicians: A Review of Prior

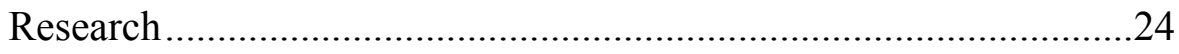

Implementation of Clinical Support Tools ...........................................2

Feedback in Group Psychotherapy Research..........................................22

"Quality Assurance” and Feedback in Group Psychotherapy: The CORE-

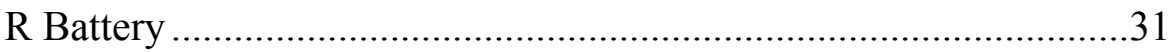

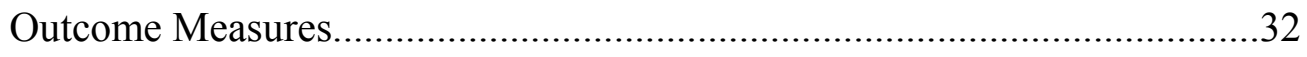

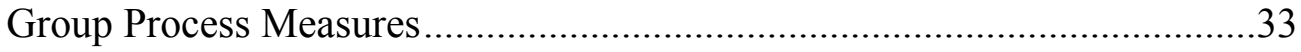


Benefits and Drawbacks of the Use of Measures in Group Psychotherapy ..35

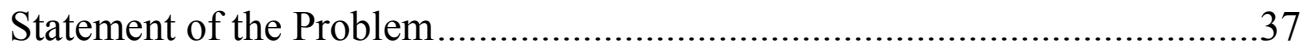

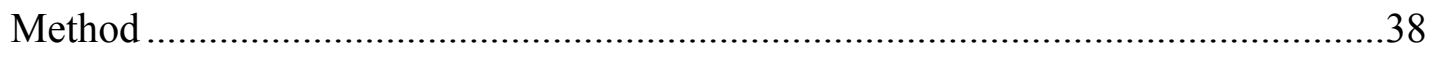

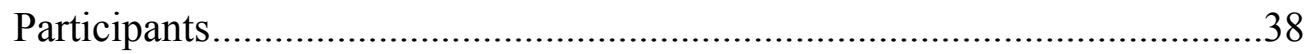

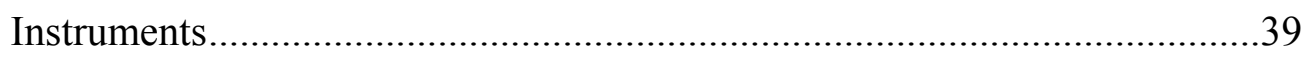

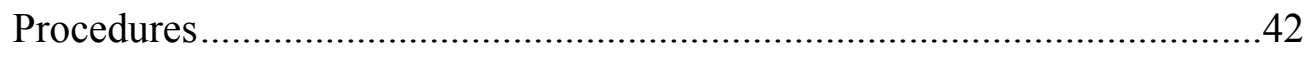

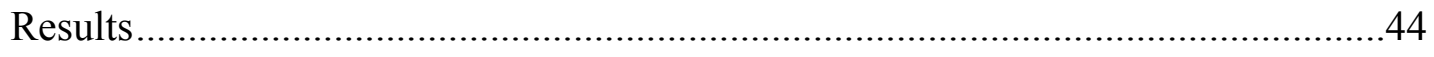

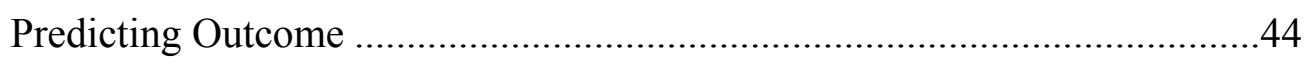

Predicting Group Relationship..........................................................45

Agreement on Group-Level Interventions ...........................................47

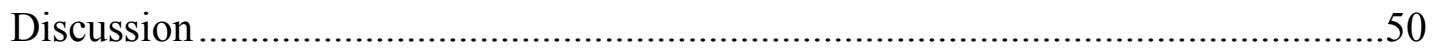

Limitations and Future Directions ......................................................53

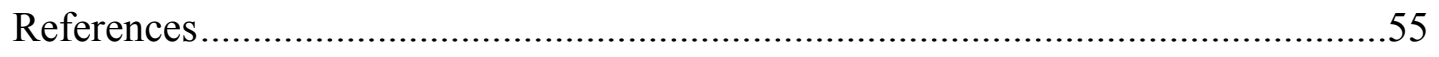

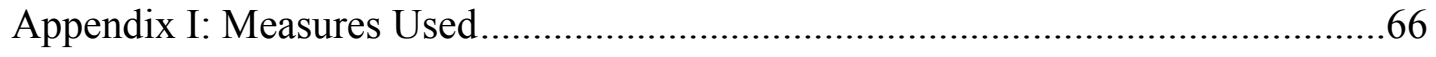

Appendix II: Prediction and Feedback Forms ................................................ 71 


\section{LIST OF TABLES}

Table 1: GQ Descriptive Statistics for Outpatient (UCC) and Inpatient (USH)

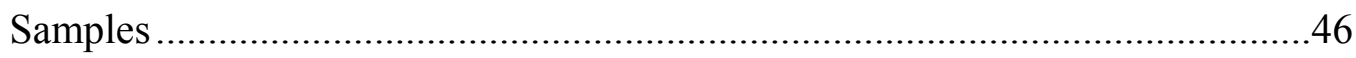

Table 2: Prediction on GQ Domains- University Counseling Center Setting ...............48

Table 3: Prediction on GQ Domains- State Hospital Setting ....................................49 


\section{LIST OF FIGURES}

Figure 1: Five Interrelated Change Processes in Group Psychotherapy........................4

Figure 2: Client Outcomes and Therapist Predictions ............................................45 


\section{Clinical Prediction in Group Psychotherapy}

As group psychotherapy has been established as an viable and cost-effective mode of treatment (Burlingame, Fuhriman, \& Mosier, 2003; Kösters, Burlingame, Nachtigall, \& Strauss, 2006), debate regarding which factors contribute to therapeutic gain by group members has spurred continuing research investigating the nature of these curative processes, their relationship to one another, and their impact on psychotherapeutic outcomes.

Recently, a revised CORE battery (Burlingame, Strauss, \& Hwang, 2008) was developed as a response to the growing pressure mounted on clinicians to use empirically based measures to track therapeutic factors and client outcomes in their groups. The aim of the CORE-R is to augment clinical judgment by providing information regarding member selection, therapeutic group processes, and member outcome (Burlingame et al., 2008). Similar empirically-based feedback systems have been implemented for clinicians working in individual psychotherapy both nationally and internationally (Barkham, Margison, Leach, Lucock, Mellor-Clark, \& Evans, 2001; Kordy, Hannover, \& Richard, 2001; Lambert, Hansen, \& Finch, 2001; Lueger, Howard, Martinovich, Lutz, Anderson, \& Grissom, 2001;).

Research examining the benefits of providing such feedback to therapists in individual therapy has shown encouraging results in regards to improving client outcome, in particular for clients who are not responding to treatment (Berking, Orth, \& Lutz 2006; Harmon et al., 2006; Hawkins, Lambert, Vermeersch, Slade, \& Tuttle, 2004; Lambert et al., 2002; Whipple et al., 2003). However, research examining the impact of providing similar feedback in group psychotherapy remains scant. 
While there are many hypothesized benefits to implementing assessment tools in group, such as those included with the CORE-R, many of these benefits have yet to be fully ascertained. Some therapists may question whether or not such measures are necessary to aid their clinical judgment, and therefore rely on their training and expertise to alter their interventions when necessary in psychotherapy. Prior research in individual therapy has provided evidence that therapists are poor predictors of client outcome (Breslin, Sobell, Buchan, \& Cunningham, 1997; Hannan, Lambert, Harmon, Nielsen, Smart, \& Shimokawa, 2005) and often misjudge clients' perceptions of the therapeutic relationship (Burns \& Auerbach, 1996).

Given the research demonstrating the difficulties in accurately predicting individual client outcome and strength of the therapeutic relationship, a similar study seems warranted in a group setting, as the therapist has even less information on each individual client when compared to dyadic treatments. Thus, we expected no better and perhaps worse predictive results in group treatment. Such a study would not only examine the importance of using outcome and clinical support feedback in group, but would also represent an important new direction in group research. Given that group has lagged behind individual therapy in implementing outcome feedback, the current study would be the first to examine group leader reaction to receiving such feedback. As such, the study could provide the necessary background to engage in a RCT similar to those conducted by researchers in individual therapy using OQ-45 outcome feedback along with CSTs. 
The current study aimed to determine whether or not the use of process and outcome measures provided new and useful information to group therapists, or whether therapists' can accurately predict these factors.

What follows is a review of the literature detailing therapeutic processes related to outcome in group psychotherapy. In addition, past studies examining the ability of therapists to accurately predict client perceptions of the therapeutic relationship and client outcome are reviewed. The chapter also focuses on the benefits of providing empirically based feedback to therapists in individual psychotherapy. The review then explores options for group therapists seeking to implement similar feedback interventions in their work, highlighting the limited research conducted regarding the usefulness of these feedback systems in group psychotherapy. The purpose of the review is to discuss how the use of assessment tools may augment clinical judgment in group psychotherapy, and the need for further research and exploration regarding the proposed benefits of using such measures.

\section{Literature Review}

\section{Factors Influencing Outcome}

In research by Burlingame, MacKenzie, and Strauss (2004), the authors propose a model detailing factors that explain treatment outcomes in group psychotherapy, including five interrelated factors: patient characteristics, structural factors, leader characteristics, formal change theory, and small-group processes (Figure 1). Patient characteristics, such as initial level of disturbance, personality, and interpersonal style have an established importance as predictors of group process (Kivlighan \& Angelone, 1992; Piper, Joyce, Rosie, \& Azim, 1994) as well as outcome (Burlingame et al., 2004; 
Yalom \& Lescsz, 1995). Structural factors refer to the establishment and maintenance of group norms, such as frequency of sessions, group settings, and the size of the group. Leader characteristics include aspects of the leader's presence in group that impact the performance of the group, including therapist warmth, empathy, and openness. These are characteristics which have been associated with group process and outcome (Hurley \& Rosenberg, 1990; Mcbride, 1995). Formal Change Theories represent the diverse therapeutic orientations, ranging from cognitive behavioral, to psycho-educational, to existential, and their impact on the psychotherapy group. These formal change theories are typically used as a framework in order to direct the therapeutic activity within the group.

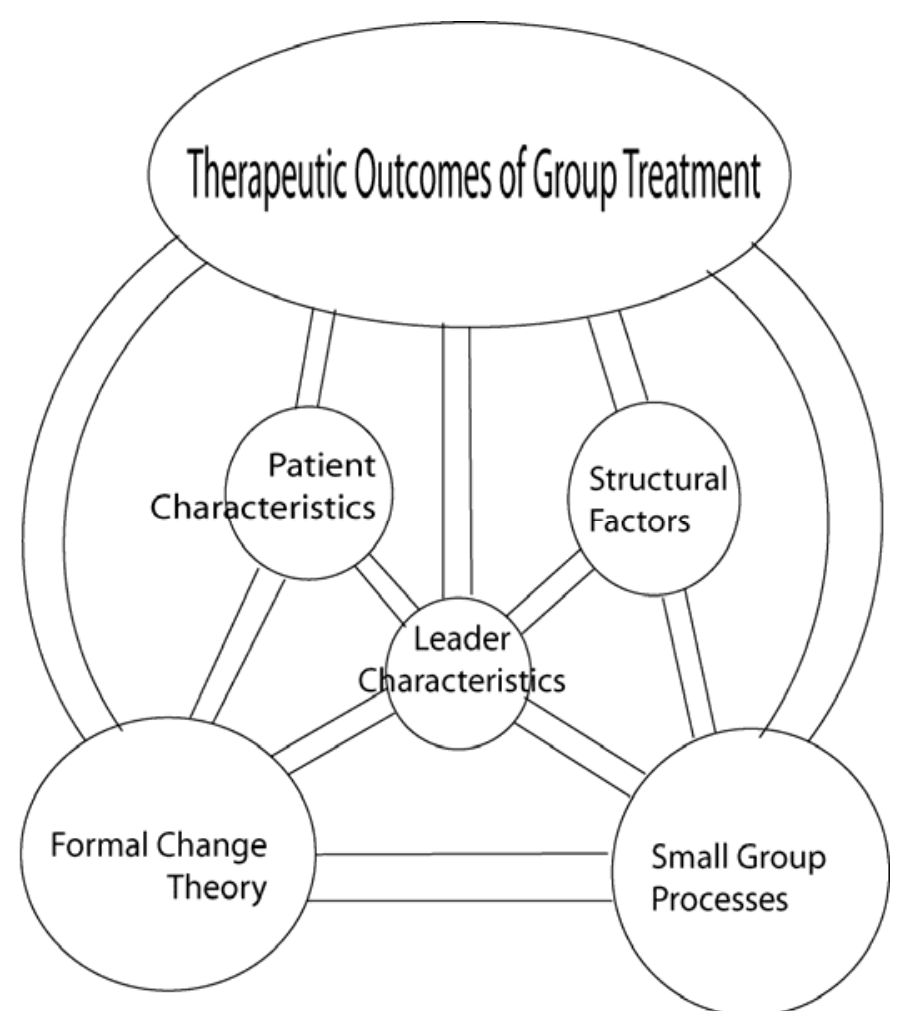

Figure 1. Five Interrelated Change Processes in Group Psychotherapy, from Burlingame,G. M., MacKenzie, K. R., \& Strauss, B. (2004). 
Small Group Processes encompass areas of the group relationship with known links to therapeutic outcome (Burlingame, Fuhriman, \& Johnson, 2002; Burlingame et al., 2004; Yalom \& Lescsz, 1995). While the study of small group processes, their definition, and their impact on outcome comprises a voluminous body of research, this brief review will focus on several of the most well-defined and empirically validated areas in terms of their impact on group outcome: Cohesion, Working Alliance, Group Climate, and Empathy (Burlingame, Johnson, \& Fuhriman, 2002; Johnson, Burlingame, Olsen, Davies, \& Gleave, 2005). While there may be considerable debate as to the precise definitions of these factors, as well as their relationships (and possible areas of overlap) with one another, each has been shown to relate to member progress and outcome.

Cohesion, one of the most extensively researched small group processes (Yalom \& Lescsz, 2005), can be defined as the sense of togetherness or 'we-ness' (Yalom \& Lescsz, 2005) of the group, comparable to the 'therapeutic alliance' described in individual therapy. However, the definition of the construct has been debated and evolved considerably across the history of group process research. Burlingame and colleagues (2002) define cohesion as the therapeutic relationship in group. As such, cohesion consists of relationships on multiple levels: member-to-group, member-tomember, member-to-leader, leader-to-group, and leader-to-leader. It also describes the sense of collaborative bonding and alliance on interpersonal levels as well as intrapersonal (group-as-whole) levels.

A number of studies have linked high levels of group cohesion with therapeutic outcome (McCallum, Piper, Ogrodniczuk, \& Joyce, 2002; Stokes, 1983; Tschuschke \& 
Dies, 1994), with Tschuschke and Dies (1994) declaring a 'linear and positive' relationship between cohesion and outcome. While these findings appear to validate the notion that cohesion is a crucial aspect of the group therapeutic relationship, other research presents more mixed results in regards to cohesion and its impact on outcome (Gillaspy, Wright, Campbell, Stokes, \& Adinoff, 2002; Kipnes, Piper, \& Joyce, 2002; Marziali, Mumoe-Blum, \& McCleary, 1997). However, much of this difficulty in establishing the relationship between cohesion and outcome may be related to the diverse definitions, operationalizations, and measures used to define cohesion (Dion, 2000).

Working Alliance, or the shared responsibility between group members and the group leader in focusing on and working towards treatment goals (Johnson et al., 2005), has a well-established relationship with outcome. However, the construct shares a degree of definitional overlap with cohesion, and much like cohesion, has been defined and measured in diverse ways in the body of group process research (Johnson et al., 2005). In studies in which working alliance is defined as group member alliance with the therapist in working towards treatment goals, this aspect of the group relationship has been found to be predictive of positive outcomes (Brown \& O'Leary, 2001; Sexton, 1993; Strauss \& Burgmeier-Lohse, 1995).

Group Climate refers to the presence of a therapeutic climate that facilitates the emotional expression and self-disclosure of group members, the responsiveness of other group members to these disclosures, and the shared meaning derived from such in-group experiences (Burlingame et al., 2002). In order to benefit from group, it is vital that an atmosphere of warmth and acceptance be provided to allow group members to express and explore the meanings of their behavior and emotional expressions in a cathartic 
manner within the group (Hurley \& Rosenberg, 1990; Mcbride, 1995). While there has been less variation in terms of defining the construct of Group Climate, one of the reasons for this is the preeminence of the Group Climate Questionnaire (GCQ; MacKenzie, 1983) in group process literature. The measure has been used in a variety of studies, with the 'Engagement' subscale found to positively predict outcome (Johnson et al., 2005; MacKenzie, Dies, Coche, Rutan, \& Stone, 1987; Ogrodniczuk \& Piper, 2003) while high scores on its conflict (measuring levels of hostility within the group) and avoidance subscales appear to be negatively correlated with outcomes (Johnson et al., 2005; Ogroduniczuk \& Piper, 2003; Phipps \& Zastowny, 1988).

Empathy, or the client's sense of being understood by the group, has gained almost universal acceptance in regards to its therapeutic value by adherents to a variety of psychotherapeutic orientations. While proponents of these orientations may define empathy in slightly different ways, it is consistently held as a curative therapeutic factor of critical importance (Burns, 1996; Mcbride, 1995; Trad, 1993). Empathy has been connected with positive outcome in a variety of studies; in one review, Orlinsky, Grawe, and Parks (1994), examined 115 studies examining the impact of empathy on outcome and found that in $72 \%$ of the studies, the clients' perception of empathy was positively related to outcome. In the group literature, Karterud (1988) as well as Hurley and Rosenberg (1990) have linked empathetic group leader qualities with positive outcomes.

\section{A New, Comprehensive Model of the Group Relationship}

While the small group processes briefly reviewed above have all been linked to therapeutic outcome for group members, little research has been done investigating the relationship between these process variables, their possible overlap, and their impact on 
one another across member-member, member-group, and member-leader levels. In an attempt to construct an empirical definition of the group relationship and assist in mitigating the considerable confusion caused by the diverse definitions of each group relationship construct, Johnson and colleagues (2005) proposed a new model of higherorder or latent constructs to describe the group relationship. In their model, four measures were used to operationalize the latent constructs: the Group Climate Questionnaire (GCQ; MacKenzie, 1983), the cohesion scale of the Therapeutic Factors Inventory (TFI; Lese \& McNair-Semands, 2000), the Working Alliance Inventory (WAI; Horvath \& Greenberg, 1989), and Empathy Scale (ES; Burns \& Auerbach, 1996). The TFI and the GCQ were used to target perceptions of member-group relationships, while the WAI and the ES corresponded to member-member and member-leader relationships. These measures were administered to 662 participants from 11 different counseling centers and personal growth groups at the American Group Psychotherapy Association (AGPA). Employing Exploratory Factor Analysis (EFA) to analyze the data from the composite questionnaires, these authors created an empirical description of the latent group relationship factors.

This model consists of three main components of the therapeutic group relationship, each subsuming a number of other components of group process (Johnson et al., 2005). The first component, positive relational bonds, represents the individual group member's emotional attachment and sense of affiliation with the other members of the group, including the therapist, and the group-as-a-whole. The second component, positive working relationships, represents the individual member's collaborative engagement in working towards treatment goals with other members, and with the therapist. The third 
component, negative relationship factors, represents aspects of the group process that may negatively impede the therapeutic work or impact member bonds with the other members, group leader, or group-as-a-whole (Burlingame et al., 2008).

Johnson and colleagues' new model is unique in its incorporation of three central aspects of the group therapeutic relationship that have previously been extensively researched and discussed in group process research: content, relationship roles, and quality.

The main content-based divisions in group psychotherapy are conceptualized as being between alliance and cohesion, as well as work and bonding processes (Johnson et al., 2005). In past studies, alliance and cohesion have been considered the primary content differentiation in group psychotherapy (Bakali, Baldwin, \& Lorentzen, 2009; Horvath \& Luborsky, 1993), until Johnson and colleague's (2005) study asserted the three-factor structure in which bonding (positive bonding relationship) and working (positive working relationship) were primary processes.

Roles in group have commonly been divided into three structured relationships: member-leader, member-member, and member group (Burlingame et al., 2004; Yalom \& Leszcz, 2005). Constructs of working alliance has commonly been defined as specific to the member-leader relationship, and group climate and cohesion have been tied to member-group relationships. The new model, however, analyze working and bonding processes as they operate amongst member-leader, member-member, and member-group relationships.

Quality of therapeutic relationship has historically been represented by one factor with a continuum from negative to positive (Tracey \& Kokotovic, 1989) or with two 
factors representing negative and positive relationship factors, respectively. In Johnson's study, the final model that provided the best fit for her data included two positive dimensions (positive bonding and positive working) and one negative dimension (negative relationship).

\section{Defining the Therapeutic Group Relationship: The Development of the Group}

\section{Questionnaire}

Following Johnson and colleagues (2005) efforts at providing a unified, empirically-based definition of the group relationship, other researchers attempted to replicate these findings across five clinical settings and four countries.

A study by Bormann and Strauss (2007) collected data from 67 inpatient psychodynamic groups drawn from 15 inpatient treatment centers in Germany and Switzerland. The test-of-model fit was analyzed for the whole clinical sample $(N=438)$ and four randomized samples to ensure the model's robustness. Most of the fit indices revealed significant differences between the hypothesized model originally proposed by Johnson and colleagues and the empirical data in four of the five tested samples.

Nevertheless, Chi-Square-Difference-Tests clearly demonstrated the predominance of the three-factor model compared to a more economical one-factor model, assuming only one general factor indicating relationship quality (therapeutic relationship). Exploratory Structural Equation Modeling (SEM) revealed a three-factor structure comparable with the original three-factor model, with only minimal modifications. While results showed that the three-factor model could not be replicated completely, the basic structure of the model was confirmed. The German sample also revealed high correlations between the four relationship factors (group climate, cohesion, alliance and empathy) and indicated 
that the three major factors (positive bonding, positive working and negative relationship) best described the complex relationships within group treatments.

A study by Bakali, Baldwin, and Lorentzen (2009) further examined the factor structure put forward by Johnson and colleagues (2005) with group members in Norway attending psychoanalytic therapy groups. The Working Alliance Inventory-Short Form, the Therapeutic Factors Inventory Cohesiveness Subscale, and the Group Climate Questionnaire-Short Form were administered to 145 patients in 18 groups three times during the life of the group. They were administered in the early (sessions 3-4), middle (10-11), and late (17-18) stages of development. One particular thrust of the study focused on differentiation of roles in group (member-leader, member-member, and member-group) and how these roles relate to specific content aspects of the therapeutic relationship.

The researchers used CFA to test five distinct factor structure models on their data. The first model aimed to examine whether or not the data would fit a one-factor model representing the aspect of quality in therapeutic relationships. The second model consisted of two factors, the working and bonding content dimensions. The third model was a direct reflection of Johnson and colleagues' three-factor model used in establishing the GQ, which consists of working and bonding content dimensions, along with a factor representing the quality of therapeutic relationships in group. The fourth model consisted of two factors represented by the group relationship as distinct from the dyadic relationship (the aspect of roles), with the dyadic relationship factor confounded within the alliance content dimension. The fifth model consisted of three factors, each based on the quality of relationships in combination with the distinct relationship roles in member- 
group and member-leader relationships. In this model the content dimension of cohesion was confounded within the member-group relationship factor and alliance was confounded within the member-leader factor.

Researchers tested the models in the early, middle, and late stages of group psychotherapy. Using multilevel CFA, the researchers found that models one, two, and four were not a good fit for the data. At the early group stage, models three and five fit the data equally well, despite not meeting conventional standards for good model fit. However, the model fit was close to acceptable, and warranted further exploration in order to seek an appropriate fit. The researchers inspected the modification indices to examine if any theoretically justifiable changes could be made. This process resulted in a sixth model combining aspects of models three and five, with the primary change being modifying the WAI Bond content dimension to load on the first and second factors. The final model consisted of three factors: factor one was labelled member-leader alliance, factor two labelled positive bonding relationship, and factor three labelled negative relationship. The primary difference in this model from Johnson and colleagues' (2005) original was that the member-leader bond was not only important to the member-leader relationship but the also to the bonding dimension of the group as a whole. This model fit exceptionally well for the early group data, CFI $=0.98, \mathrm{TLI}=0.97$, and RMSEA $=$ 0.04. The Chi-Square test was nonsignificant, $\chi^{2}(38, N=139)=46.56, p=.16$.

When tested with data from the middle sessions (10-11) of therapy, the model showed adequate fit, $\chi^{2}(38, N=130)=61.3, p=.01$, with CFI $=0.95$, TLI $=0.94$, and RMSEA $=0.07$. However, researchers discovered that during the middle sessions the WAI bond did not significantly load onto the second factor (positive bonding 
relationship) and that it loaded more strongly on the first factor (member-leader alliance). Thus, the model of greatest fit during the middle sessions approximated model five as described above. For data from the later sessions of therapy, model six showed an excellent fit, with a nonsignificant chi square test, $\chi^{2}(38, N=130)=42.3, p=0.29$, CFI $=0.99, \mathrm{TLI}=0.99$, and RMSEA $=0.03$. When tested with data from later sessions of therapy, the factor loadings were similar to those from the middle sessions, with WAI Bond loading significantly to the first factor but not the second.

The findings suggest that the member-leader relationship and the emotional bond between patient and therapist was important to both working and bonding aspects of the alliance, as well as to positive bonding of the group as a whole in early sessions, with lesser importance in later sessions. The researchers explained that this may be due to the fact group leaders in the study were particularly active in early sessions (Bakali et al., 2009) and met individually with group members for five sessions before group began. This unique group format may have led to the divergence between their model of best fit and Johnson's model.

Despite these differences, the study supported a three-factor structure of the therapeutic group relationship, similar to the factor structure originally put forth by Johnson et al. (2005). However, the study also indicated that the member-leader relationship in group may operate as its own relative independent therapeutic process, further highlighting the need in group psychotherapy research to examine specific relationship roles and how they relate with group therapeutic processes.

A study by Krogel, Burlingame, Chapman, Renshaw, Gleave, and Beacher (2009) aimed to again test Johnson and colleagues' factor structure of the group relationship and 
ultimately use it to create a measure of the group relationship with the capability of tracking group relationship factors linked to outcome. The final purpose of the study was to create a measure that is empirically based, relevant to clinicians, and easy to administer and interpret. The measure was dubbed the Group Questionnaire (GQ).

The development of the GQ consisted of two steps: First, using empirical data and clinical judgment, a team of experienced group researchers and clinicians worked to pare down and select the most relevant and psychometrically sound items from Johnson's original set of 60 . Second, the GQ factor structure was tested and revised using Confirmatory Factor Analysis (CFA) and data from three populations: outpatients from a University Counseling Center (UCC), non-patient participants from the American Group Psychotherapy Association (AGPA), and inpatients from the Utah State Hospital (USH) (Krogel et al., 2009).

In selecting which items to omit, empirical analyses were first conducted, followed by a thorough review of the proposed items. First, the research team reviewed Johnson's statistical analyses of the original 60 questions used in creating the model. The researchers then identified from an empirical perspective which items from each first order factor were the strongest and which items could be dropped due to redundancy. In general, items with small factor loadings or high correlations with other items were identified for consideration of being dropped (Krogel et al., 2009).

Following the empirical analysis, the researchers met and discussed the content domain of each subscale as reflected by the items it contained. A clinically relevant definition was provided to describe each scale after reviewing the items that comprised the scale. Items were considered for inclusion based on their clinical relevance to these 
refined construct definitions and their empirical support. Using this process, items were selected, eliminated, reworded, and combined to create the 40-item version of the Group Questionnaire (Krogel et al., 2009).

Researchers administered the reduced 40-item measure to three populations in order to test the validity of Johnson's model and explore the psychometric properties of the new measure. Participants included 486 individuals from the three group populations: outpatient university student, non-clinical, and inpatient. Because the GQ had never been used in an inpatient setting, the USH population was selected to potentially broaden the scope of the GQ and to test its viability with the inpatient population.

Data were then analyzed using CFA to assess the goodness-of-fit of Johnson's model to each of the populations separately and as a whole. Results from the CFA of the 40-item GQ provided an inadequate fit to the data Poor fit was also found when a separate CFA was performed on each of the three sample populations. However, expected relationships between first and second order factors were found by calculating correlations and regression weights among all the subscales and testing them for statistical significance using a onetailed test. Model divisions between levels of the group relationship (member-member, member-leader, and member-group) were found to provide a good fit to the data when second order factor items were related directly and first order factors were excluded.

In order to explore a better fit for the model, the 40-item GQ was further refined by removing 10 items due to small regression weights or small factor loadings with their associated first order factor. These 30 items were again subjected to the previously conducted statistical analyses. Results from the CFA of the refined GQ provided a good 
fit to the data, replicating the good fit Johnson and colleagues (2005) found with the proposed model in her study. This suggests that the refined 30-item GQ measurement model adequately represented the relevant theoretical constructs in the samples used in Krogel's study.

The final study was conducted by Bormann and Strauss (2009) and explored the validity and structural fit of the German version of the 30-item Group Questionnaire (GQ). The study was conducted in two parts. First, structural fit was applied to a dataset from the earlier German multi-site study (Bormann \& Strauss, 2007). Using LISREL, the fit indices indicated a very good structural fit $\left(\chi^{2}=629, d f=348, p<.001 ; \mathrm{CFI}=0.96\right.$; $\mathrm{NFI}=0.94, \mathrm{SRMR}=0.05 ; \mathrm{RSMEA}=0.04)$. The reliabilities (internal consistency, Cronbachs' Alpha) of the three GQ-subscales, positive bonding $(\alpha=0.92)$, positive working $(\alpha=0.90)$, and negative relationship $(\alpha=0.77)$, were also acceptable.

The second focus of the study evaluated the validity of the German GQ by relating it to four gold-standard process measures in use in Germany. Five-hundred inpatients from 64 groups and 8 different German hospitals took part in the study. The scale inter-correlations between the GQ-subscales and the subscales of the measures mentioned above showed all significant results and ranged from $r=0.42$ to $r=0.56(p<$ 0.01; Pearson correlation). The structural fit using LISREL was applied once more on the new dataset and supported the results from earlier studies. Again the fit indices indicated a good structural fit $\left(\chi^{2}=818, d f=376, p<.001 ; \mathrm{CFI}=0.97 ; \mathrm{NFI}=0.95\right.$, $\mathrm{SRMR}=0.06 ; \mathrm{RSMEA}=0.05)$. Also the reliabilities of the three GQ-subscales using Cronbachs' Alpha showed good results that are comparable with Krogel et al.'s study: 
positive bonding ( $\alpha=0.92$ ), positive working ( $\alpha=0.89$ ), and negative relationship $(\alpha=0.79)$.

The studies described above all have endeavoured to provide a parsimonious and empirically-based definition of group therapeutic processes. The final goal of this line of research is to clarify the nature of the group relationship and to develop a comprehensive measure of the group relationship with the capability of providing clinicians useful feedback about the functioning of their groups.

\section{Trends in Patient-focused Research: A Response to "Evidence-Based Practice"}

It is a common reality in today's mental health treatment climate that clinicians are asked with increasing frequency to use objective measures of process and outcome in order to demonstrate the effectiveness of their work (Burlingame et al., 2008; Lambert \& Ogles, 2004). RCT's conducted using OQ-45 feedback in concert with CST's in individual therapy represent an effort to address this push to practice in a demonstrably empirically supported manner.

The current study is the connecting step between the aforementioned individual therapy RCT's and group treatment. Specifically, it tests the usefulness of outcomebased feedback in tandem with information regarding client perception of the therapeutic relationship in the group. The study can be seen as a preliminary step before an RCT is initiated evaluating the effects of using outcome and clinical support feedback in groups. A brief review of the RCT's from the individual literature provides a context for the present study.

Driven by the need to meet the demands of evidence-based practice, with an awareness of the limitations of efficacy research attempting to establish empirically- 
supported treatments, patient-focused research (Howard et al., 1996; Lambert, 2001) attempts to improve practice by providing systematic information regarding individual patient's progress and status in therapy to clinicians. Patient-focused research adheres to a model of care where clinicians can either step-up or decrease the intensity of treatment based on the individual's response to treatment (Lambert, 2007). Patient-focused research connects research with clinical practice, advocating methods to track patient progress over the course of treatment and providing this information to therapists as a form of 'quality assurance' in order to inform their therapy and alter its course when necessary.

A number of patient-focused research programs have attempted to put this methodology into practice. Researchers at Northwestern University have incorporated hierarchical linear modeling to estimate projected treatment response for patients using a battery of measures (the COMPASS) assessing client symptoms, therapeutic bond between client and therapist, well being, and life functioning (Lueger et al., 2001). Patients complete these forms repeatedly during the course of therapy, and therapists are provided with detailed reports of the measures detailing their patients' progress and estimated treatment outcome.

In an effort to develop a national quality-assurance program, researchers in England have also incorporated patient-focused research methods in clinical practice through the development of the Clinical Outcomes in Routine Evaluation-Outcome Measure (CORE-OM). The measure assesses four primary areas of patient functioning: subjective well-being, symptoms, functioning, and risk (Barkham et al., 2001). Therapists are provided with feedback from the CORE-OM's results informing them of 
estimates of how groups of service providers compare to normative samples (Evans, Connell, Barkham, Marshall, \& Mellor-Clark, 2003). In Germany, the StuttgartHeidelberg quality assurance model (Kordy et al., 2001) represents another example of clinicians attempting to monitor patient symptoms and provide this information to therapists. Studies examining the effectiveness of this feedback program (Percevic, Lambert, \& Kordy, 2004) indicated that providing feedback to therapists reduced the treatment length needed to achieve clinically significant improvement. Similar research in Germany by Berking, Orth and Lutz (2006) found that systematic feedback given to therapists in an inpatient setting improved outcomes for their patients at an increased rate over non-feedback groups.

\section{The 'Dose-Response' Model in Tracking Therapy Outcomes}

Research by Howard et al. (1996) and Hansen, Lambert, and Forman (2002), has endorsed a dose-response model conceptualizing therapeutic change and evaluating treatment effectiveness. In this model, therapy functions as a 'dose' that is provided to the patient in varying degrees to achieve the desired 'response.' In applying the doseresponse model, tracking the recovery or deterioration of clients in therapy facilitates the prediction of eventual outcome. Jacobson and Truax (1991) point to "clinical significance" as an important gauge of treatment effect when monitoring outcome. They developed a statistical index (known as the reliable change index, or RCI) to determine whether a change score on an outcome instrument is likely to indicate actual or clinically significant change $(p<0.05)$. Lambert (1998) developed algorithms based on the RCI. By applying this index to repeated outcome measures completed by patients, it is possible 
to identify patients who are benefiting from therapy, deriving no benefit from therapy, or deteriorating over the course of therapy.

Research by Lambert and colleagues has focused on incorporating RCI's with a brief outcome questionnaire, the OQ-45. Using Hierarchical Linear Modeling (HLM) with OQ-45 data collected from 11,492 patients from a variety of therapy settings, researchers developed change trajectories with the OQ-45 designed to project the course of treatment based on session by session OQ-45 ratings (Finch, Lambert, \& Schaajle, 2001). Using these trajectories, therapists using the OQ-45 can receive feedback on whether or not their clients are responding in an expected manner to therapy. When a client is not responding in an expected manner, a therapist receives a 'signal alarm,' a red (deteriorating in therapy) or yellow (experiencing no significant change in therapy) warning message that their client is at risk for an unfavorable outcome in therapy. This information allows the therapist to use the objective feedback from the OQ-45 in order alter their therapeutic interventions or step-up the intensity of therapy in response to the individual's negative response to treatment (APA 2007; Lambert, 2007).

\section{Benefits of Feedback}

There is considerable evidence supporting the proposition that feedback can effectuate desirable behavior change, as feedback interventions have shown a mild to moderate impact on improving outcomes in studies spanning a wide variety of disciplines (Kluger \& DeNisi, 1996; Sepyta, Riemer, \& Bickman, 2005). Feedback appears to be of particular benefit when there is a discrepancy between the performance or progress of a subject and the expected standards for their performance (Sepyta, Riemer, \& Bickman, 2005). In psychotherapy feedback research, the same principle appears to hold true: 
feedback interventions have their greatest impact on treatment outcomes for patients not progressing as expected in therapy (Lambert, 2003), a number ranging from $5-10 \%$ in various studies (Hansen, Lambert, \& Foreman, 2002).

\section{Clinical and Empirical Prediction Methods}

Due to therapists' struggles in simply identifying deteriorating patients, feedback is particularly useful in assisting therapists with not-on-track patients. The prognostic accuracy of therapists' predictions is often problematic (Breslin et al., 1997). Clinicians have a tendency to fail to recognize deteriorating patients and overestimate the effectiveness of the treatment they provide (Hannan et al., 2005; Norcross, 2003). A notable example of this tendency was demonstrated in a 2003 survey conducted by Dew and Reimer, in which 143 counselors were asked to rate their job performance on a scale from A+ to F. Sixty-six percent rated themselves as an A or better, without a single respondent rating themselves as below average.

In a meta-analysis comparing clinical to actuarial judgment in predicting human behavior across a number of fields, Grove, Zald, Lebow, Snitz, and Nelson (2000) found that actuarial prediction is typically as accurate, if not more accurate, than clinical prediction. In the scattered instances in which clinical judgment proved to be more accurate than mechanical methods, the authors attributed this success to the fact that clinicians had received more data than mechanical prediction. Despite these examples, actuarial prediction proved to be more accurate and reliable in the clear majority of studies, whether in medical or psychological settings, with both experienced clinicians and trainees. This systematic superiority suggests that the use of such methods may 
assist clinicians seeking to inform their own clinical judgment with additional data in order to gain insight into the progress of their patients.

\section{Can Therapists Accurately Predict Client Status and Outcome?}

In a study by Hannan et al. (2005), 48 therapists working in a University Counseling Center were asked to predict which of their patients were likely to worsen over the course of therapy. Over a three-week period, therapists were asked to predict outcomes based on clinical judgment alone for patients in four main categories: (a) recover, (b) improve but not recover, (c) make no progress in treatment, or (d) get worse. Therapists were also asked to rate the progress of their patients over multiple therapy sessions during a three-week period. Again, prognosis was divided into four categories: (a) recovered and ready for termination, (b) improving as expected, but in need of continued treatment, (c) making no progress or poor progress, and (d) getting worse.

Results indicated that therapists rarely predicted deterioration. Of the 550 patients participating in the study, three $(0.01 \%)$ were predicted by their therapists to deteriorate, with only one of the three actually concluding treatment in a deteriorated state. In contrast, actuarial assessment procedures using the OQ-45 were able to accurately predict $77 \%$ of deteriorated cases. Out of all participating clients, there was a $7.8 \%$ deterioration rate (26 clients). These results suggest that therapists tend to underestimate the number of patients at risk for negative outcome in therapy, while demonstrating an unfounded optimism regarding positive client outcomes. Additionally, number of sessions with the client before making the prediction did not impact accuracy in any way.

In regards to predicting client progress, empirical prediction via the OQ-45 again proved to more accurately identify signal-alarm cases. While therapists judged that 16 
clients $(5 \%)$ had worsened at the time of a specific session, positive outcomes were predicted for all but three of these 16 patients. While the OQ-45 was able to predict 20 of the 26 clients at risk for deterioration during therapy, therapists successfully identified only five of the 26 as having worsened during therapy at the time of prediction.

Additional research in individual therapy has shown that therapists often perform poorly not only at predicting outcome, but at understanding how their patients perceive aspects of the therapeutic relationship. A review by Burns and Auerbach (1996) discussed several studies in which therapists, patients, and clinical supervisors were asked to rate the empathy level of the therapist during the same session. The researchers reported that there was no significant agreement among patients, therapists, or supervisors on ratings of therapist empathy using the same measures. Additionally, in the majority of the reviewed empathy studies, only client ratings of therapist empathy were related to eventual outcome.

In the limited number of studies focusing on this topic in group psychotherapy research, therapists have demonstrated similar struggles in accurately gauging how group processes are perceived by group members. In a study by Jenkins, Keefe, and Rosato (1971), therapist and patient ratings of therapist effectiveness, therapist-member relationship, direction and control provided by the therapist in the group, and perceived use of techniques were compared four times over the course of 16 sessions for two outpatient psychotherapy groups. The researchers found that the correlation between therapist and patient awareness in each of the four factors was modest at best, and was strongest during the initial administration of the measures. This finding presented evidence against the researchers' initial hypothesis that over the course of therapy 
familiarity with the group and its members would cause patient and group leader reports on each measure to correlate at a higher level. Correlations were strongest in regards to measures of therapists' use of direction and control, but were not significant at any point for measures of the therapeutic relationship or therapist effectiveness. The findings suggest that therapists may easily be unaware of client perceptions of therapeutic group relationship factors, and that the accuracy of their perceptions does not appear to improve even after extended exposure to their groups.

This research underscores the need for objective measurement tools to aid in identifying clients responding poorly to treatment, and supports past studies detailing the superiority of actuarial versus clinical judgment in predictive tasks (Grove et al., 2000). As therapists are rarely accurate in their predictions of which of their clients may deteriorate in treatment and how the therapeutic relationship is perceived by clients, these tools can provide valuable information that can inform treatment in ways that may improve outcome.

\section{Providing Client Progress Feedback to Clinicians: A Review of Prior Research}

A number of studies have analyzed the potential benefits of providing feedback to therapists on the progress of their patients in individual therapy. While this line of research is still relatively new and untested in group psychotherapy, several previous studies have incorporated the OQ-45 as a measure of outcome and an indicator of whether or not the patient is responding in an expected manner to treatment in individual therapy. These studies have indicated that providing feedback to therapists about their clients significantly reduces the number of clients leaving therapy in a deteriorated condition (Harmon et al., 2006; Hawkins et al., 2004; Lambert et al., 2001; Lambert et 
al., 2002; Whipple et al., 2003). The following is a review of five controlled studies examining the effects of providing patient progress feedback to therapists using the OQ45 , as well as a recent attempt to replicate this research in a group setting using an outcome and process measure to guide the therapist in adjusting treatment as needed.

Feedback studies conducted using the OQ-45 share several common characteristics (Lambert, 2007). First, data was collected from consecutive cases in routine care regardless of patient characteristics or diagnosis. Second, patients were randomly assigned to experimental (feedback) or control (non-feedback) groups. Third, therapists participating in the study endorsed a variety of theoretical orientations. Fourth, clinicians varied considerably in their experience level and training. Fifth, therapists saw patients from both feedback and control groups in a within-blocks experimental design. Sixth, outcome measures were constant in each study. Seventh, length of treatment was determined by therapists and clients, without any external session limits imposed on study participants.

The first feedback study ascribing to this methodology was conducted by Lambert and colleagues (2001). Patients were divided into two groups: a feedback group, whose progress was monitored using the OQ-45 outcome measure with results provided to therapists prior to each session, and control (TAU) groups, whose outcomes were monitored on a session-by session basis using the OQ-45, with feedback withheld from therapists. Both groups were assigned within therapist blocks, so all participating therapists received feedback and non-feedback clients. Feedback was provided from OQ45 results, with color coded graphs (green, yellow, and red) indicating the progress and anticipated trajectory of patient recovery. Green signals were given for patients 
progressing as expected in therapy, yellow signals for not progressing as expected in therapy, and red signals for clients at risk for terminating therapy in a deteriorated condition. Patients exhibiting a 'yellow' or 'red' signal on their OQ-45 results were flagged as 'signal alarm' patients, or not-on-track (NOT) for positive outcomes in psychotherapy. The study focused on these not-on-track signal alarm patients, hypothesizing that NOT patients whose therapists received feedback on their progress would terminate therapy with better outcomes than NOT patients in the non-feedback control group. After controlling for initial severity, results suggested that NOT patients in the feedback condition reported levels of improvement significantly higher than those in TAU control groups. Sixteen percent of NOT patients in the non-feedback group achieved results sufficient to qualify for clinically significant change via RCI formulas; in contrast, $26 \%$ of NOT patients in the feedback group achieved clinically significant change as measured by the OQ-45 (Lambert et al., 2001). Results also indicated that NOT patients in the feedback group stayed in therapy on average for more sessions than NOT control group patients.

In a replication of this research, Lambert et al. (2002) confirmed the results of the initial study, demonstrating that feedback to therapists about their NOT patients improved the outcomes of these patients at significant rates higher than those of NOT patients in non feedback groups. Once again, feedback interventions centered on assisting therapists in identifying patients who are not responding to therapy appeared to provide the most significant improvement to outcomes. 


\section{Implementation of Clinical Support Tools}

Despite these improvements in preventing patient deterioration, results indicated that most patients who had been signaled as NOT during the study had terminated therapy still showing significant levels of distress. In an effort to further improve outcome through feedback interventions for these patients, Whipple et al. (2003) developed Clinical Support Tools (CST's), based on stepwise problem-solving strategies frequently used in medical fields to assist clinicians making decisions regarding managing drug dosage, diagnosis, preventative care, and client outcomes (Hunt, Haynes, Hanna, \& Smith, 1998). In Whipple and colleagues' research, these CST's were designed as empirically-based problem solving strategies arranged hierarchically in decision trees. The decision trees direct the therapist's focus to factors known to be related to psychotherapeutic outcome.

In designing the problem-solving strategies, Whipple et al. (2003) focused on three therapeutic factors that could be assessed and used to provide feedback and treatment suggestions for therapists: therapeutic alliance, readiness to change, and degree of social support. Decision trees provided to therapists encouraged therapists to: (a) examine ratings of therapeutic alliance, (b) examine ratings of client motivation, (c) examine client ratings of social support, (d) to consider diagnostic reformulation, and (e) to consider referral for medical consultation. Suggested interventions outlined in a Clinical Support Tools Manual were available to assist therapists in solving specific problems identified in this manner.

Outcomes were compared between non-feedback NOT controls, a feedback NOT group, and a feedback, plus CST, NOT group. Results indicated that when the CST 
intervention was added to the feedback group, outcomes were incrementally enhanced over the feedback-only group. Providing progress feedback and CST feedback in tandem reduced deterioration rates among those identified as NOT from $21 \%$ to $8 \%$ and increased success rates from $21 \%$ to $50 \%$ (Whipple et al., 2003).

Continuing this line of investigation, Hawkins and colleagues (2004) examined the therapeutic impact of providing both therapists and patients with ongoing feedback regarding their progress in psychotherapy. Hawkins and colleagues (2004) compared outcomes for non-feedback control groups, therapist-only feedback groups, and for patients who received feedback on their progress along with their therapists. The results of Hawkins and colleagues' study suggest that supplying patients, in addition to therapists, with feedback improved outcome not only for clients who were predicted to have a poor treatment response (NOT), but also appeared to improve outcome for clients who were on track (OT), a finding that had not been produced in previous feedback studies.

Harmon et al. (2007) built on research by Hawkins et al. (2004) and Whipple et al. (2003). In this study, Harmon and colleagues explored the benefits of using CSTs and providing feedback to both patients and therapists. Harmon and colleagues also examined the possible usefulness of the measures used to inform the CST decision trees (assessing therapeutic alliance, motivation, and social support) as predictors of outcome when administered pre-treatment. Finally, Harmon and colleagues investigated the effects of providing progress feedback to both therapists and patients in an attempt to replicate Hawkins et al.'s (2004) added effect on enhancing outcome in the Patient/Therapist feedback condition, but failed to replicate these findings. One 
possibility that may explain the struggle to reproduce these results could center on the populations used for each study. Hawkins and colleagues' study was conducted in an outpatient clinic, while Harmon and collegues' study was conducted in a University Counseling Center. Patients in the outpatient clinic tended to exhibit higher levels of distress, thus perhaps presenting more room for improvement via feedback interventions. The differences between these populations may have impacted the differential in results in the two studies.

A study conducted by Slade, Lambert, Harmon, Smart, and Bailey (2008), used CSTs and added an alternative measure for motivation and an additional scale measuring perfectionism. The study also examined whether immediate, computer-generated feedback was superior to time-delayed feedback in improving outcome for NOT clients. Results suggested that the use of the new CSTs improved outcome compared to TAU, replicating similar results in studies by Harmon and Whipple.

\section{Feedback in Group Psychotherapy Research}

As has been mentioned above, there is little research examining the impact of feedback interventions on clinical psychotherapy groups. One study by Davies, Burlingame, Johnson, Barlow, and Gleave (2008) explored the effects of providing group-level feedback to therapists and group members using two process measures: The Group Climate Questionnaire - Short Form (GCQ; MacKenzie, 1983) and The Curative Climate Instrument (CCI; Fuhriman, Drescher, Hanson, \& Henrie, 1986). The OQ-45 was given before the commencement of group therapy to establish a baseline for individual clients assigned to group, then administered again as a measure of final 
outcome after 13 weeks of group therapy or after they terminated services, which ever occurred first.

Members completed both the GCQ and the CCI at the end of each group session for 13 weeks. At the beginning of each session, group leaders passed out feedback forms describing member responses on the measures and discussed these results with the group. As part of the feedback condition, individual member responses remained anonymous; results from the process measures were discussed in general terms (i.e., 'it looks like the group experienced a great deal of conflict last week') instead of singling out specific group members. Group leaders participating in the study led two or more groups, with half of their groups receiving feedback, and the other half receiving no feedback from the measures they completed. The researchers hypothesized that groups in the experimental condition would show greater improvement on measures of group climate, cohesion, and outcome than controls. They also hypothesized that improvement would be most significant for clients who perceived their groups more negatively in their initial assessments.

Contrary to researchers' hypotheses, the results from the study appear to indicate that group members in the feedback condition showed no significant improvement in terms of group process or outcome. In fact, the feedback condition was associated with higher levels of conflict as measured by the GCQ in group. In addition, the experimental condition had no effect on outcome for clients who were initially most distressed.

There are a number of factors that may have impacted the results of the study; sample sizes were small, and there was extreme variability of outcome for members in each group, leading to high levels of within-subject error. Another explanation for the 
lack of a significant effect for the feedback intervention is the nature of the feedback itself. It is possible that group members receiving feedback about their negative perceptions of the group relationship may have induced feelings of alienation. As feedback was presented in an open-ended manner, without a concrete discussion of possible solutions to problems in group functioning, the feedback may have led to feelings of helplessness and eventual detachment from the group.

The study is of unique importance due to the lack of research analyzing the effects of measure-based feedback on process and outcomes in group psychotherapy. However, further research and exploration is clearly needed in order to explore the impact of such interventions on therapists and group members. Research in group psychotherapy has lagged behind research in individual psychotherapy in exploring possible methods of tracking member progress and providing this information to therapists in an effort to improve outcomes. While such feedback implementation systems have been, and continue to be honed for therapists in individual psychotherapy, similar initiatives are underway from organizations such as the American Group Psychotherapy Association (AGPA) in order to provide similar tools for group psychotherapists.

\section{“Quality Assurance” and Feedback in Group Psychotherapy: The CORE-R Battery}

In response to the growing need for reliable and valid assessment of outcome, process, and client variables related to therapeutic change, a task force of researchers working with the American Group Psychotherapy Association (Burlingame et al., 2008) identified the most valid and reliable group assessment tools. Their goal is to make clinicians and researchers aware of assessment resources in three main categories: (a) The 
preparation and selection of group members; (b) the assessment of group member outcomes; and (c) tracking group-level processes (Burlingame et al., 2008).

The following is a brief review of a selection of the most well-established outcome and process instruments. The following instruments were singled out by an AGPA task force of researchers (Ogrodniczuk, 2005) as most useful and well-researched. Ogrodniczuk (2005) reviewed outcome measures for the AGPA task force, while Joyce (2005) reviewed group process measures.

\section{Outcome Measures}

Outcome Questionnaire-45. The Outcome Questionnaire-45 (OQ-45; Lambert et al., 1996) is a self-report instrument which measures three domains of functioning typically endorsed by psychologically distressed persons, including subjective discomfort, interpersonal relationships, and social role performance. The OQ-45 provides subscales scores for each of these areas of functioning, as well as a total score reflective of an overall level of psychological distress. The total score ranges from zero to 180 with higher scores indicating greater pathology.

Inventory of Interpersonal Problems. The IIP-32 (Horowitz, 1999) is a 32-item measure assessing problems in interpersonal functioning. The IIP-32 assesses interpersonal problems along eight subscales reflecting a variety of problematic relational styles: domineering, vindictive, cold, socially avoidant, non-assertive, exploitable, overly nurturing, and intrusive. In addition, the IIP provides a total score indicating an overall level of interpersonal problems.

Rosenberg Self-Esteem Scale. The Rosenberg Self-Esteem Scale (Rosenberg, 1965 ) is a 10-item measure of patient self-esteem assessing global self-worth and self- 
acceptance. The RSES produces a total score ranging from 10 to 40, with higher scores indicating higher self-esteem.

Group Evaluation Scale. The GES (Hess, 1996) measures the group members' general feelings towards the group, feelings of stability or instability, the ability to explain problems in front of the group, the helpfulness of other group members, and the feelings of being understood, autonomous and responsible. Scoring results in a total score that varies between seven and 35, with higher scores indicating greater benefit from the group.

\section{Group Process Measures}

Working Alliance Inventory. The 36-item WAI (Horvath \& Greenberg, 1989) evaluates the quality of the therapeutic relationship between an individual member and the group leader. Scoring the WAI yields three subscales assessing the therapeutic relationship: (a) the Bond subscale, evaluating the level of trust and acceptance present in the member-therapist relationship; (b) the Tasks subscale, evaluating the level of patienttherapist agreement on behaviors and activities during the group session; and 3) the Goals subscale evaluates the level of patient-therapist agreement and sense of cooperation in working towards the overarching goals of treatment. The WAI also yields a total score reflecting the overall quality of the patient-therapist alliance.

Empathy Scale. The 10-item ES (Persons \& Burns, 1985) assesses a patient's perception of the therapist's warmth, empathy, and caring. Items rate for the presence of both positive and negative empathy factors in the member-therapist relationship. Scores on the ES have been associated with outcome in psychotherapy (Persons \& Burns, 1985). 
Group Climate Questionnaire-Short Form. The Group Climate

Questionnaire-Short Form (MacKenzie, 1983) is a self-report measure that purports to assess individual group member's perceptions of the group's therapeutic environment. The GCQ contains 12 items rating on a seven-point Likert scale indicating extent of agreement, ranging from not at all (0) to extremely (6). The GCQ consists of three factor-analytically derived subcales (engagement, avoidance, and conflict), representing behavioral descriptions of group climate in clear, simple language, requiring little interpretation (MacKenzie, 1983). The engagement subscale consists of items that rate levels of self-disclosure, cognitive understanding, and confrontation in the group. The avoidance subscale purports to measure how much the group members avoid responsibility for their change processes. The conflict subscale purports to measure interpersonal conflict and distrust (MacKenzie, 1983).

Cohesion Subscale of Therapeutic Factors Inventory. The TFI (Lese \& MacNair-Semands, 2000) assesses the range of therapeutic factors originally put forth by Yalom (2005). The nine items of the TFI-Cohesion subscale reflect the group members' sense of belonging and experiences of acceptance, trust, and cooperation in the group. The TFI measures the group members' bond relationship with the group-as-a-whole.

Cohesion to the Therapist Scale. The CTS (Piper, Marrache, \& Lacroix, 1983), a nine-item scale measuring group members' perceptions of the therapist's qualities as a group leader, provide scores on three subscales. The positive qualities subscale assesses the members' perceptions of the therapist's trustworthiness and likeability. The personal compatibility subscale reflects the members' perceptions of the therapist's similarity, familiarity, and friendship potential. The dissatisfaction with the therapist's role subscale 
reflects the members' perception of problems with the therapist's activity, attentiveness, or expressiveness.

\section{Benefits and Drawbacks of the use of Measures in Group Psychotherapy}

In addition to the externally imposed pressures placed upon therapists to incorporate empirical measures into their clinical practice that demonstrate treatment effectiveness, there are a number of proposed benefits associated with using such measures (Burlingame et al., 2008; Joyce, 2006; Mckenzie \& Livesley, 1986). One significant benefit of tracking member outcome and process is that it allows the therapist to focus on individuals not responding to treatment in an anticipated manner. As was heretofore discussed, therapists tend to struggle in identifying these patients without the help of objective measures (Hannan et al., 2005), which may allow problems to go unnoticed. Group therapy is unique in that there is a complex interplay of variables the therapist must track during a given session. The sheer complexity of these variables may prevent the therapist from being able to accurately track individuals who are failing to engage the group for their therapeutic benefit. Feedback from assessment tools can help the therapist identify those members who struggle and intervene appropriately.

Another significant benefit is that outcome and process measures provide objective viewpoints documenting the therapeutic processes of the group, member progress, and member outcomes in a way that minimizes bias on either side. When the results of the measures are provided to both therapists and group members, the instruments can be used to encourage discussion and patient involvement in the treatment process, which may help build the therapeutic alliance. 
Another benefit of employing such assessment tools is that patients may feel more comfortable expressing opinions or feelings on a measure than they would during group. This feedback can increase therapist understanding of patient issues and therefore enhance the therapeutic process. Process and outcome assessments can also be used to clarify goals in therapy and facilitate new behavior through impartial documentation of possible issues or problems in the group.

Additionally, the implementation of these measures may give patients an increased sense that the group therapist is committed to treatment and interested in cooperating with group members in an effort to maximize the effectiveness of their treatment. Use of these measures can also assist in the training of novice group therapists, as it allows them to focus on specific, basic therapeutic group factors.

While these proposed benefits may aid group therapists as they work to monitor group outcomes and processes, certain drawbacks are to be expected when implementing such measures in a clinical setting as well. A common complaint is that they take time away from the group (Elder, 2006) and as a consequence may detract from the therapeutic experience for group members. Another concern is that assessment instruments used in group sometimes fail to provide useful, direct feedback for group members and leaders (Elder, 2006). There is even some indication that negative feedback from assessments may cause more harm than good (Davies et al., 2008). In these cases feedback can increase anxiety levels of group members and cause them to withdraw further from the group. The use of evaluative tools such as outcome measures also raises the risk of such assessments being used unfairly to compare therapists in ways that could lead to adverse administrative decisions (Burlingame et al., 2008). 


\section{Statement of the Problem}

The regular use of process and outcome measures, and their impact on the experience of both group leaders and members, has yet to be fully studied and analyzed. With this in mind, it may be presumptuous to state in concrete terms the precise benefits and drawbacks of implementing such a feedback system. The purpose of the above review was to discuss a number of prominent issues pertinent to the potential benefit of implementing feedback based on objective measures in group psychotherapy.

There is no doubt, however, that a complex intermingling of variables contribute to successful outcomes in group psychotherapy. The group therapist must attend to all these factors in order to maximize the effectiveness of their groups. Because of the complexity of these factors, therapists may often fail to identify struggling clients. Their perceptions of relationship and process factors in therapy may also tend to vary a great deal from their patients' views.

In individual psychotherapy, researchers have attempted to solve this problem by adopting patient-focused methods for tracking outcome and providing feedback to therapists. This empirically-based feedback, often used in concert with the guidance of clinical support tools, has shown to have a significant positive effect on outcome for noton-track (NOT) patients. Applying this method to group therapy, researchers have worked to identify the best measures and develop new measures when necessary to assist clinicians in their work by providing information on various aspects of group functioning. The study proposes the following hypotheses:

1. No significant relationship will exist between actual client outcomes (reliably improved, no significant change, or reliably worse) and therapist prediction of client 
outcomes at the 3rd group session (allowing time for each group to become stable in terms of group membership and allowing group leaders time to become familiar with their members).

2. There will be no relationship between therapist and group member ratings of the group relationship at the 3rd, 6th, and 9th group session.

3. There will be no relationship between therapist and independent rater assessment in the use of specific empirically supported group-level interventions used during the 3rd, 6th, and 9th group sessions.

\section{Method}

\section{Participants}

Participants were 135 individuals receiving treatment at two settings. Eight outpatient psychotherapy groups and eight group leaders (4 co-leadership teams) participated from the Brigham Young University Counseling and Career Center (CCC) and 12 inpatient groups and six group leaders participated from the Utah State Hospital (USH). Six of the CCC therapists were male. Self-reported ethnicity yielded seven Caucasians and one Hispanic leader. All CCC groups had a primary and secondary group leader; most of the leaders were doctoral-level clinicians with two secondary group leaders being doctoral students. Average experience was 11 years, with a range from 3 to 33 years. Groups were typically process-oriented and were closed to new members after data collection began. $61 \%$ of the participants were female and the average age was 23 . Most participants reported ethnicity as Caucasian (86\%) while minority representation was 4\% Hispanic, $6 \%$ Asian/Pacific Islander, and 4\% "Other." The majority of group members were full-time university students referred for problems common to college 
population, such as depression, anxiety, adjustment, and relationship issues. As an incentive to participate in the study, members received ten dollars in cash at the close of the study for completing forms.

The USH therapists were all Master's level clinicians representing social work, nursing and recreational therapy. Groups were led by a single clinician. All leaders were Caucasian with gender being evenly split. Leaders reported an average 18 years of experience ranging from 2 to 31 years. Groups were primarily psycho-educational in nature and focused on self-care and social skills, guided by a structured manual. Membership was open, with new members being added and others being discharged from the hospital.

According to USH census data collected during the study the average age was 39 (range $22-89, S D=15$ ) with $53 \%$ male and $47 \%$ female. Reported ethnicities were $89 \%$ Caucasian, 1\% African American, 5\% Hispanic, 2\% American Indian, 1\% Asian /Pacific Islander, and $1 \%$ unknown. Patients were typically diagnosed with some combination of psychotic, bipolar, and/or affective disorders.

\section{Instruments}

Outcome Questionnaire-45 (OQ-45). The OQ-45 (Lambert et al., 1996), a 45item client report measure of psychological distress, was used with the UCC population to assess group member therapy outcomes. The measure has a reported internal consistency of 0.93 and a test-retest reliability of 0.84 , well within adequate ranges (Lambert et al., 2004). The measure provides scores in the domains of subjective discomfort, interpersonal relationships, and social role performance, as well as an overall level of distress score. On the OQ-45, a total score of 63 or more indicates symptoms of 
clinical significance. Reliable change on is indicated when a client's score changes by 14 points or more. Clinically significant change is indicated when a client's score changes by 14 points or more and moves below the clinical cutoff score.

Severe Outcome Questionnaire(S-OQ). The progress and outcomes of group members from the USH was tracked using the Severe Outcome Questionnaire (S-OQ) (Burlingame, Thayer, Lee, Nelson, \& Lambert, 2007). The S-OQ is a modified version of the OQ specifically designed for use among inpatient populations. The S-OQ assesses patient functioning in four domains of psychological functioning: subjective discomfort, interpersonal relationships, and social role performance, and severe functional impairment. The measure also yields a total score indicating overall level of distress. The S-OQ has an internal consistency reliability of 0.95 (Burlingame et al., 2007). On the S-OQ, a score of 56 or more indicates clinical levels of distress and functioning. Reliable change is indicated when a client's score changes by 14 points or more. Clinically significant change is indicated when a client's score changes by 14 points or more and moves below the clinical cutoff score.

Group Questionnaire (GQ). Client perception of the therapeutic relationship was measured using the GQ. The GQ is a 30-item self-report measure of the therapeutic relationship in group using three factors: positive bonding relationship, positive working relationship, and negative relationship, across three structural dimensions: memberleader, member-member, and member-group (Krogel et al., 2009). The factor structure of the measure has been supported across several studies using inpatient, outpatient and nonclinical groups in the United States, Norway, and Germany (Bakali, Baldwin, \& Lorentzen, 2009; Bormann \& Strauss, 2007; Bormann \& Strauss, 2009; Krogel et al., 
2009). The measure is completed using a seven-point Likert scale ( $1=$ Not True At All, $2=$ A Little True, $3=$ Slightly True, $4=$ Somewhat True, $5=$ Moderately True, $6=$ Considerably True, $7=$ Very True). The completed measure yields scores on each of the three dimensions (positive bonding relationship, positive working relationship, and negative relationship) with no total score. Data from Krogel et al.'s (2009) study of three populations (inpatient, counseling center, and nonclinical groups) was used to develop population-specific norms to create feedback sheets allowing group leaders to compare member scores with relevant normative group scores.

Group Psychotherapy Intervention Rating Scale (GPIRS). Therapist interventions were measured by the GPIRS (Chapman, Baker, Porter, Burlingame, \& Thayer, 2010; Sternberg \& Trijsburg, 2005). The measure is the result of an international cooperative to develop a measure of leader interventions for domains known to be related to better outcomes in group treatment (Burlingame, Fuhriman \& Johnson, 2002) with the long-term goal to create a group clinical support tool. The GPIRS is a rater-completed measure that assesses interventions on three subscales: group structuring, verbal interactions, and creating and maintaining a therapeutic emotional climate. Each item on the GPIRS describes a specific, empirically-supported intervention (Chapman et al., 2010). Conceptualizing the GPIRS as a clinical support help, each subscale corresponds with a subscale of the GQ. Group structuring interventions correspond with positive working relationship, verbal interaction interventions correspond with positive bonding relationship, while creating and maintaining a therapeutic emotional climate interventions correspond with both the positive bonding and negative relationship. Thus, the measures 
can be used in tandem to provide problem solving ideas for therapists when they note low scores on the GQ.

In scoring the GPIRS, raters assess: (a) whether the intervention occurred, and (b) the clarity or strength of the intervention. In a previous study (Chapman et al., 2010) the GPIRS has shown concurrent validity with rater measures of the therapeutic quality of group member interaction (the Hill Interaction Matrix, Hill, 1965) and member-reported levels of engagement, conflict and avoidance in the group (Group Climate Questionnaire, MacKenzie, 1983). Both criterion measures have been linked to both group processes and outcome (Burlingame et al., 2003; Fuhriman \& Burlingame, 2000).

\section{Procedures}

Upon being debriefed and giving consent to participate during pre-group interviews, clients completed outcome instruments prior to their first group session and following the ninth session. Following the third, sixth, and ninth session of their groups, group leaders left the group room early and research assistants administered the GQ. Members could opt out at any time without impacting their participation in the group. GPIRS ratings were based upon videos (UCC) or live observation (USH) of the third, sixth, and ninth sessions. Because the USH participants occasionally required extra assistance in completing the measures, a research assistant was available to help participants when needed. Small books of coupons that could be exchanged within the facility for hospital-approved food items were used as an incentive to participate in the study at the USH.

Each group leader had two concurrent groups. In the "feedback" group, the leader received outcome and group relationship feedback sheets for each group member 
based on normative values from their setting, as well as group-level summaries of their interventions following the third, sixth, and ninth group sessions. In the second “prediction" group, leaders received no feedback, but were asked to predict final outcome results (reliably improved, no significant change, or reliably worse), member perceptions of the group relationship using the three GQ subscales (positive bonding relationship, positive working relationship, and negative relationship) and to assess their use of own interventions from the three GPIRS subscales (group structuring, verbal interaction, and creating and maintaining a therapeutic emotional climate). Leaders were asked to predict outcome after the $3^{\text {rd }}$ group session. The $3^{\text {rd }}$ session was selected to allow the leader to gain familiarity with group members and to allow group membership to become stable. Prediction of member perceptions of the group relationship and leader interventions was collected after the $3^{\text {rd }}, 6^{\text {th }}$, and $9^{\text {th }}$ sessions to evaluate if accuracy improved over time.

Rater Training. Eight GPIRS raters received training over a four week period. Raters were eight upper level psychology undergraduate students and ranged between 20 and 27 years of age. Raters were instructed regarding confidentiality policies and the theoretic basis for the measure. A series of video-taped group therapy sessions were rated and inter-rater reliability was assessed. Before each new practice video, the ratings on the previous video were discussed as a group in order to gain consensus. The process was repeated until an inter-rater reliability coefficient of 0.80 or above was achieved. Inter-rater reliability assessment and calibration occurred during the course of data gathering in order to maintain an inter-rater agreement. 


\section{Results}

\section{Predicting Outcome}

We predicted no significant relationship would exist between actual client outcomes (reliably improved, no significant change, or reliably worse at the end of the nine week data collection cycle) and therapist prediction following the third group session based upon previous studies from the individual treatment literature. In prediction groups, 31 group members from the UCC population and 33 group members from the USH population filled out valid outcome measures at the commencement and at the close of their group treatment. Of the 31 UCC group members, 23 scored in clinical range upon entering the group, of which 5 achieved clinically significant improvement by the $9^{\text {th }}$ session of the group. Of the 33 USH group members, 25 scored in clinical range, with 3 achieving clinically significant improvement.

Figure 2 details actual and predicted outcomes from both settings. The Kappa rater agreement supported our prediction $(K=-.83$; significance $=.260 ; d f=49)$; there was no relationship between therapist ratings and actual outcome. We tested both sites separately to determine if therapists at one setting were more accurate and found no site differences. Of the 10 cases that were classified as reliably worse following treatment, not a single case was accurately identified by a group therapist. Therapists predicted that 31 of the 49 group members for whom final outcome scores were obtained would show reliable improvement; out of those predicted, $13 \%$ (4 of 31) were accurately predicted. Therapists were the most successful predicting the most frequent treatment outcome group, no significant change. They predicted this 15 times with eight of those predictions (53\%) being accurate. 


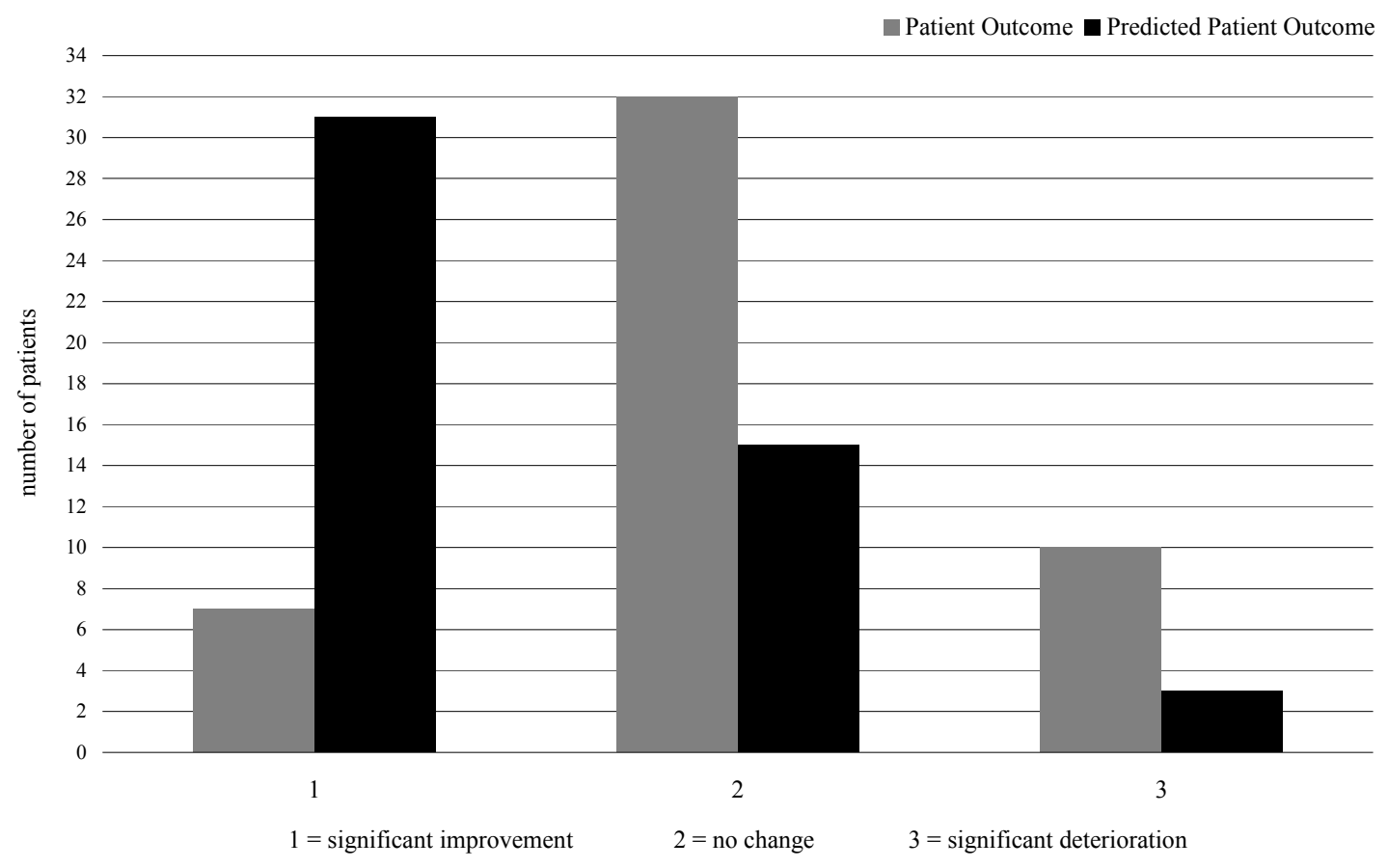

Figure 2. Client Outcomes and Therapist Predictions.

\section{Predicting Group Relationship}

As a group, leaders rated group relationship lower than clients on the positive bonding and positive working subscales. Counseling center leaders predicted more negative relationship than members endorsed, while state hospital leaders predicted lower negative relationship scores than members endorsed. Moreover, state hospital group members exhibited a higher level of variability in their GQ responses than counseling center members replicating Krogel et al.'s (2009) findings (see table 2). 
Table 1

Descriptive Statistics for outpatient (UCC) and inpatient (USH) samples

\begin{tabular}{|c|c|c|c|c|c|}
\hline & $N$ & Minimum & Maximum & Mean & $S D$ \\
\hline Positive Bonding- UCC Patient Rating & 56 & 3.60 & 7.00 & 5.7384 & .79189 \\
\hline Positive Working- UCC Patient Rating & 56 & 1.50 & 7.00 & 5.1272 & 1.07859 \\
\hline Negative Relationship- UCC Patient Rating & 56 & 1.00 & 5.67 & 2.1220 & .83907 \\
\hline Positive Bonding- UCC Therapist Prediction & 57 & 2 & 6 & 4.60 & 1.223 \\
\hline Positive Working- UCC Therapist Prediction & 57 & 2 & 7 & 4.86 & 1.288 \\
\hline Negative Relationship- UCC Therapist Prediction & 57 & 1 & 5 & 2.98 & 1.142 \\
\hline Positive Bonding- USH Patient Rating & 57 & 1.40 & 6.80 & 4.7303 & 1.25928 \\
\hline Positive Working- USH Patient Rating & 55 & 1.00 & 7.00 & 4.7260 & 1.72244 \\
\hline Negative Relationship- USH Patient Rating & 54 & 1.00 & 5.90 & 2.4880 & 1.27513 \\
\hline Positive Bonding- USH Therapist Prediction & 55 & 1 & 7 & 3.75 & 1.280 \\
\hline Positive Working- USH Therapist Prediction & 54 & 1 & 6 & 3.81 & 1.480 \\
\hline Negative Relationship- USH Therapist Prediction & 54 & 1 & 5 & 2.22 & 1.127 \\
\hline
\end{tabular}


We predicted no relationship between group member ratings on the three GQ subscales (positive bonding, positive working, and negative relationship) and therapist ratings. This hypothesis was tested using mixed-model analysis to control for nonindependent group member data (Kenny, 2002). Our hypothesis was largely supported with only 3 of 18 therapist prediction showing agreement with member scores. Counseling center therapists and members showed agreement at the ninth session on the positive bond and work subscales and at the sixth session on the negative relationship subscale (see table 2). No agreement was found on any subscale for the state hospital group leaders (see table 3 ).

The mixed model used to conduct the analyses in the present study help to control for intraclass correlations in the data. However, in an effort to greater understand the relationships between group membership and GQ scores, intraclass correlations were calculated for each of the three analyses conducted with the GQ. For the analysis on the Positive Bonding domain, we found a modest correlation of .20, indicating that $21.2 \%$ of the variance in member GQ scores is between groups. However, ICC scores for the other two domains (.002 for Positive Working and .08 for Negative Relationship) were considerably lower, accounting for . $2 \%$ and $8 \%$ of the variance in member GQ scores, respectively.

\section{Agreement on Group-Level Interventions}

We predicted that there would be no relationship between the group level interventions endorsed by group leaders and the independent rater's scores. This hypothesis was tested using mixed-model analysis and due to the smaller sample size data from both sites was combined, not separated by session number. There was no 
Table 2

Prediction on GQ Domains- University Counseling Center Setting

\begin{tabular}{|c|c|c|c|c|c|c|c|}
\hline Setting & Domain & Session & $\begin{array}{l}\text { Estimate of } \\
\text { Fixed Effects }\end{array}$ & Std. Error & $d f$ & $t$ & $p$ \\
\hline UCC & Positive Bonding & 3 & -0.014836 & 0.120729 & 47.288 & -0.123 & 0.903 \\
\hline $\mathrm{UCC}$ & Positive Bonding & 6 & 0.218918 & 0.126960 & 35.359 & 1.724 & 0.093 \\
\hline $\mathrm{UCC}$ & Positive Bonding & 9 & 0.434642 & 0.097233 & 48.092 & 4.470 & $0.000 *$ \\
\hline UCC & Positive Working & 3 & 0.116657 & 0.158337 & 41.014 & 0.737 & 0.465 \\
\hline UCC & Positive Working & 6 & 0.152095 & 0.159491 & 25.322 & 0.954 & 0.349 \\
\hline $\mathrm{UCC}$ & Positive Working & 9 & 0.504839 & 0.147277 & 31.279 & 3.428 & $0.002 *$ \\
\hline UCC & Negative Relationship & 3 & 0.137280 & 0.149593 & 46.478 & 0.918 & 0.364 \\
\hline UCC & Negative Relationship & 6 & 0.620178 & 0.211751 & 21.368 & 2.929 & $0.008^{*}$ \\
\hline UCC & Negative Relationship & 9 & 0.152028 & 0.140521 & 45.105 & 1.082 & 0.285 \\
\hline
\end{tabular}

Note. * Correlation is significant at the 0.05 level (2-tailed). 
Table 3

Prediction on GQ Domains- State Hospital Setting

\begin{tabular}{|c|c|c|c|c|c|c|c|}
\hline Setting & Domain & Session & $\begin{array}{l}\text { Estimate of } \\
\text { Fixed Effects }\end{array}$ & Std. Error & $d f$ & $t$ & $p$ \\
\hline USH & Positive Bonding & 3 & 0.172666 & 0.141072 & 32.366 & 1.224 & 0.230 \\
\hline USH & Positive Bonding & 6 & -0.229368 & 0.181823 & 30.129 & -1.261 & 0.217 \\
\hline USH & Positive Bonding & 9 & 0.516995 & 0.316738 & 27.538 & 1.632 & 0.114 \\
\hline USH & Positive Working & 3 & -0.159370 & 0.167953 & 26.582 & -0.949 & 0.351 \\
\hline USH & Positive Working & 6 & 0.123379 & 0.179085 & 28.458 & 0.689 & 0.496 \\
\hline USH & Positive Working & 9 & 0.252313 & 0.197534 & 19.785 & 1.277 & 0.216 \\
\hline USH & Negative Relationship & 3 & 0.054305 & 0.166010 & 42.418 & 0.327 & 0.745 \\
\hline USH & Negative Relationship & 6 & 0.056474 & 0.318754 & 35.087 & 0.177 & 0.860 \\
\hline USH & Negative Relationship & 9 & -0.156201 & 0.282517 & 37.600 & -0.553 & 0.584 \\
\hline
\end{tabular}


significant relationship between therapist and independent raters for the group structuring $(F=.14, d f=16, p=.71)$, verbal interaction $(F=.94, d f=18, p=.34$, and emotional climate subscales $(F=1.38, d f=17, p=.25)$ of the GPIRS.

\section{Discussion}

A limited number of studies in individual therapy have found that therapists do not accurately predict client outcome or the therapeutic relationship when both are compared against client self-report measures (Burns \& Auerbach, 1996; Hannan et al., 2005). This study, while distinct in method and modality, echoes these findings in a group setting. The current study produced similar results to Hannan et al.'s (2005) study, in that therapists tended to under-predict the incidence of deterioration in treatment. Therapists failed to accurately predict treatment failure for the 10 clients in the prediction sample that were classified as reliably worse upon the termination of the group. Like Hannan et al. (2005) therapists demonstrated a similar optimistic bias predicting positive gains for a majority of their clients, which were largely not supported by the final results. Unlike the Hannan et al. (2005) study, we had had fewer group members and therapists and so the findings are supportive but need to be replicated with a larger sample. Sample size is frequently mentioned challenge in group research (Burlingame, 2010). Indeed, due to logistical limitations, the method used in the study by Hannan and colleagues could not be completely duplicated in a group format. However, under these limitations we were able to examine similar questions to those analyzed in Hannan and colleagues' study and garner meaningful results.

Group therapists predictions did not agree with how group member's perceived the therapeutic relationship in their groups, particularly in the early part of the groups' 
development. The importance of this finding is that early phases of the group are when group members are most likely to drop out (Yalom \& Lescsz, 2005). Interestingly, group leaders tended to view the therapeutic relationship from a less positive perspective than the group members. This underestimation of the positive bonds and working relationships early in the group may lead group leaders to delay interventions until they believe members and the group are "ready" thereby delaying potential gains.

Therapists' worst prediction was on the negative relationship subscale, which captures the level of conflict, hostility, and negative empathy felt by members. Members who perceive their groups as hostile, unwelcoming, and rejecting are at greater risk for dropping out of the group (Yalom \& Lescsz, 2005) and therapists' apparent inability to accurately predict client responses may hinder them from offering interventions to improve the group experience for these members. Like the aforementioned findings, this result needs further replication before we can accept them; however, they agree with earlier research in both group (Jenkins, Keefe, \& Rosato, 1971) and individual (Burns \& Auerbach, 1996) therapy.

One unexpected finding was the improvement in prediction over time by UCC therapists. For the positive bonding and positive working domains of the GQ, These therapists demonstrated a significant increase in agreement with member scores by the ninth session. While agreement was less accurate in early and middle sessions, the improvement by the end of the groups may be due to two factors. First, increased familiarity with group members over time is likely to increase accuracy of the perceptions. This result was not found with state hospital leaders who had higher rates of dropout and had new members join midway through the group, decreasing their 
familiarity with group members. It is interesting that this finding supports the earlier prediction from the Jenkins et al. (1971) study nearly forty years ago.

A second explanation could be the feedback therapists were receiving in their "feedback" group. Therapists received three reports during the study describing member responses on the GQ. These reports could have improved the accuracy of their prediction by familiarizing leaders with how group members respond to the GQ, thereby altering knowledge and improving their agreement with "prediction" groups.

There was also little agreement between the therapist and rater on the interventions used during a given group session. This finding provides initial support for the use of clinical support helps like the GPIRS in group in a manner parallel to CSTs use in individual therapy (Harmon et al., 2006; Hawkins et al., 2004; Whipple et al., 2003). The measure may be useful to heighten leader awareness of interventions that may, in turn, be used for problem areas identified by the GQ. The GPIRS could be used in tandem with the GQ, as GPIRS subscales correspond with the subscales of the GQ. For example, interventions from the (GPIRS) structuring subscale could be used to improve member (GQ) positive working, interventions from the verbal interactions subscale could be used to improve member positive bonding, and interventions from the emotional climate subscale could be used to improve member positive bonding and reduce negative relationship.

The current study represents a new direction in group research, and echoes findings from individual therapy settings indicating the importance of augmenting clinical judgment with feedback from outcome and clinical support measures. The study is unique in its use of outcome feedback with groups. Results indicated that feedback 
from these measures provided therapists with unique and unexpected information about their groups. Given the results, we believe that the study provides support for the potential usefulness of providing outcome and process feedback to leaders and implementing measures on a more regular basis in group practice and research. The results of the current study provide a bridge between patient-based outcome research in individual therapy and a replication of this research in group.

\section{Limitations and Future Directions}

Limitations of the current study included high group dropout rates, particularly for the USH population. Participating groups at the USH were often in flux, dropping and adding members throughout the nine-week group cycle. This may have made the prediction tasks more difficult for USH group therapists. Another limitation was the lack of diversity in the samples used in the study, as the study focused solely on university counseling center and inpatient groups. Larger samples of group members as well as therapists would assist in providing information on whether or not years of clinical experience and/or training aids therapist prediction. Another limitation is the restricted range of responses by group members on the GQ measure which tended to be skewed towards high levels of positive bonding and positive working in the groups, with very low levels of negative relationship factors. While this may be reflective of actual member experiences in the groups, the lack of variability decreased the likelihood of finding significant therapist prediction effects, as the lack of variability lowered the probability of finding significant results via the mixed-model analysis.

The current study is an initial step towards replicating RCT's examining the impact of providing outcome feedback and clinical support tools to therapists in 
individual therapy (Harmon et al., 2006; Hawkins et al., 2004; Whipple et al., 2003). The study provides initial support for the use of feedback, but the potential benefits have yet to be explored in a group setting. The next step in the current line of research is to incorporate the OQ-45 in concert with clinical support tools such as the GQ and GPIRS in examining the impact of providing feedback on group member outcome. 


\section{References}

Bakali, J., Baldwin, S., \& Lorentzen, S. (2009). Modeling group process constructs at three stages during psychotherapy. Psychotherapy Research, 19(3), 332-343.

Barkham, M., Margison, F., Leach, C., Lucock, M., Mellor-Clark, J., Evans, C. (2001). Service profiling and outcomes benchmarking using the CORE-OM: Toward practice-based evidence in the psychological therapies. Journal of Consulting and Clinical Psychology, 69, 184-196.

Berking, M., Orth, U., \& Lutz, W. (2006). How effective is systematic feedback of treatment progress to the therapist? An empirical study in a cognitive-behavioraloriented treatment setting. Zeitschrift für Klinische Psychologie und Psychotherapie, 35, 21-29.

Bormann, B., \& Strauß, B. (2007). Group climate, cohesion, alliance, and empathy as components of the therapeutic relationship within group psychotherapy - Test of a multilevel model. Gruppenpsychotherapie und Gruppendynamik, 43, 1-20.

Bormann, B., \& Strauß, B. (2009, June). The German Group Questionnaire: A multi-site validation study. Paper presented at the annual meeting of the Society for Psychotherapy Research, Santiago, Chile.

Breslin, F., Sobell, L. C., Buchan, G., \& Cunningham, J. (1997). Toward a stepped-care approach to treating problem drinkers: The predictive validity of within-treatment variables and therapist prognostic ratings. Addiction, 92(11), 1479-1489.

Brown, P. D., \& O'Leary, K. D. (2001). Therapeutic alliance: Predicting continuance and success in group treatment for spouse abuse. Journal of Consulting and Clinical Psychology, 68, 340-345. 
Burlingame, G. M. (2010). Small group treatments: Introduction to special section. Psychotherapy Research, 20(1), 1-7.

Burlingame, G. M., Fuhriman, A., \& Mosier, J. (2003). The differential effectiveness of group psychotherapy: A meta-analytic perspective. Group Dynamics:Theory, Research, and Practice, 7(1), 3-12.

Burlingame, G. M., MacKenzie, K. R., \& Strauss, B. (2004). Small group treatment: Evidence for effectiveness and mechanisms of change. In M. Lambert (Ed.), Bergin and Garfield's Handbook of psychotherapy and behavior change. Wiley: NY.

Burlingame, G. M., Furhiman, A., \& Johnson, J. (2002). Cohesion in group psychotherapy. In J. Norcross (Ed.), A guide to psychotherapy relationships that work (pp. 71-88). Oxford: Oxford University Press.

Burlingame, G., Strauss, B., Hwang, A. (2008) The CORE battery: Revised by the American group psychotherapy association. In G. Lo Coco, Claudia Prestano \& G. Lo Verso, (Eds.) L'efficacia clinica delle psicoterapie di gruppo. Milano, Italy: Rafaella Cortina. (pp 183-194)

Burlingame, G., Thayer, S., Lee, J., Nelson, P., \& Lambert, M. (2007). The administration and scoring manual for the S-OQ. OQ Meaures, LLC.

Burns, D. D., \& Auerbach, A. (1996). Therapeutic empathy in cognitive-behavioral therapy: Does it really make a difference? In P. M. Salkovskis (Ed.), Frontiers of cognitive therapy (pp. 135-164). New York: Guilford. 
Chapman, C., Baker, E., Porter, G., Burlingame, G. \& Thayer, S. (2010). Rating group therapist interventions: The validation of the Group Psychotherapy Intervention Rating Scale. Group Dynamics: Theory, Research, and Practice, 14(1), 15-31.

Davies, D. R., Burlingame, G. M., Johnson, J. E., Gleave, R. L., \& Barlow, S. H. (2008). The effects of a feedback intervention on group process and outcome. Group Dynamics: Theory, Research, and Practice, 12(2), 141.

Dew, S., \& Riemer, M. (2003). Why inaccurate self-evaluation of performance justifies feedback interventions. In L. Bickman (chair), Improving outcomes through feedback intervention. Symposium conducted at the $16^{\text {th }}$ Annual Research Conference, A System of Care for Children's Mental Health: Expanding the Research Base. Tampa: University of South Florida, The Louis de la Parte Florida Mental Health Institute, Research and Training Center for Children's Mental Health.

Dion, K. L. (2000). Group cohesion: From "field of forces" to multidimensional construct. Group Dynamics, 4(1), 7-26.

Elder, J., Beecher, M., Burlingame, G. \& Walbridge, M. (2006, August). Group research participation among group therapists. Presentation to the American Psychological Association. New Orleans, LA.

Evans, C., Connell, J., Barkham, M., Marshall, C., \& Mellor-Clark, John. (2003). Practice-based evidence: Benchmarking NHS primary care counseling services at national and local levels. Clinical Psychology and Psychotherapy, 10, 374-388. 
Finch, A. E., Lambert, M. J., \& Schallje, B. G. (2001). Psychotherapy quality control: The statistical generation of expected recovery curves for integration into an early warning system. Clinical Psychology and Psychotherapy, 8, 231-242.

Gillaspy, J. A., Wright, A. R., Campbell, C., Stokes, S., \& Adinoff, B. (2002). Group alliance and cohesion as predictors of drug and alcohol abuse treatment outcomes. Psychotherapy Research, 12, 213-229.

Grove, W. M., Zald, D. H., Lebow, B. S., Snitz, B. E., \& Nelson, C. (2000). Clinical versus mechanical prediction: a meta-analysis. Psychological Assessment, 12, 1931.

Hannan, C., Lambert, M. J., Harmon, C., Nielsen, S. L., Smart, D. W., Shimokawa, K., et al. (2005). A lab test and algorithms for identifying clients at risk for treatment failure. Journal of Clinical Psychology: In Session, 61, 155-63.

Hansen, N. B., Lambert, M. J., \& Forman, E. M. (2002). The psychotherapy doseresponse effect and its implications for treatment delivery services. Clinical Psychology Science \& Practice, 9, 329-343.

Harmon, S. C., Lambert M. J., Smart, D. W., Hawkins, E. J., Nielsen, S. L., Slade, K, et al. (2007). Enhancing outcome for potential treatment failures: Therapist-client feedback and clinical support tools. Psychotherapy Research, 17, 379-392.

Hawkins, E. J., Lambert, M. J., Vermeersch, D. A., Slade, K., \& Tuttle, K. (2004). The effects of providing patient progress information to therapists and patients. Psychotherapy Research, 31, 308-327.

Hess, H. (1996). Two methods for estimating the effectiveness of group psychotherapy. In: B. Strauss, J. Eckert, V. Tschuschke (Eds.), Methoden der empirischen 
gruppentherapieforschung-Ein handbuch (pp. 142-158). Opladen, Westdeutscher Verlag.

Horowitz, L. M. (1999). Manual for the Inventory of Interpersonal Problems. San Antonio: The Psychological Corporation.

Horvath, A. O., \& Greenberg, L. S. (1989). Development and validation of the Working Alliance Inventory. Journal of Counseling Psychology, 36, 223-233.

Howard, K. I., Moras, K., Brill, P. L., Martinovich, Z., \& Lutz, W. (1996). Evaluation of psychotherapy: Efficacy, effectiveness, and patient progress. American Psychologist, 51, 1059-1064.

Hunt, D. L., Haynes, B., Hanna, S. E., \& Smith, K. (1998). Effects of computer-based clinical decision support systems on physician performance and patient outcomes. Journal of the American Medical Association, 280, 1339-1346.

Hurley, J. R., \& Rosenberg, D. B. (1990). Group members' gains in acceptance of self and others associated with leader's behavior. Genetic, Social, and General Psychology Monographs, 116(4), 413-434.

Jacobson, N. S., \& Truax, P. (1991). Clinical significance: A statistical approach to defining meaningful change in psychotherapy research. Journal of Consulting and Clinical Psychology, 59, 12-19.

Jenkins, J. L., Keefe, T., \& Rosato, L. W. (1971). Therapists' awareness of how group therapy patients perceive them. Corrective Psychiatry and Journal of Social Therapy, 17(1), 17-24.

Johnson, J. Burlingame, G. M., Olsen, D., Davies, R., \& Gleave, R. L. (2005). Group climate, cohesion, alliance, and empathy in group psychotherapy: Multilevel 
structural equation models. Journal of Counseling Psychology, 52(3), 310-321.

Joyce, A. (2005). The revised CORE Battery: Assessment of group therapy process. Group Circles, 2, 4-6.

Karterud, S. (1988). The influence of task definition, leadership, and therapeutic style on inpatient group cultures. International Journal of Therapeutic Communities, 9, 231-247.

Kipnes, D. R., Piper, W. E., Joyce, A. S. (2002). Cohesion and outcome in short-term psychodynamic groups for complicated grief. International Journal of Group Psychotherapy, 52, 483-509.

Kivlighan, D. M., Jr., \& Angelone, E. O. (1992). Interpersonal problems: Variables influencing participants' perception of group climate. Journal of Counseling Psychology, 39(4), 468-472.

Kluger, A. N., \& DeNisi, A. (1996). The effects of feedback interventions on performance: A historical review, a meta-analysis, and a preliminary feedback intervention theory. Psychological Bulletin, 119, 254-284.

Kordy, H., Hannover, W., \& Richard, M. (2001). Computer assisted feedback drivenquality management for psychotherapy: The Stuttgart-Heidelberg model. Journal of Consulting and Clinical Psychology, 69, 173-183.

Kösters, M., Burlingame, G. M., Nachtigall, C., \& Strauss, B. (2006). A meta-analytic review of the effectiveness of inpatient group psychotherapy. Group Dynamics: Theory, Research, and Practice, 10(2), 146-163.

Krogel, J., Burlingame, G. \& Chapman, C., Renshaw, T., Beecher, M., Gleave, R. (2009). The Group Questionnaire: A clinical and empirical measure of group 
relationship. Paper presented at the annual meeting of the Society for Psychotherapy Research.

Lambert, M. J. (1998, August). Patterns of patient improvement: Implications of research for treatment planning and responsible social policy. Paper presented at the Seventeenth World Conference of Psychotherapy, Warsaw, Poland.

Lambert, M. J., \& Ogles, B. M. (2004). The efficacy and effectiveness of psychotherapy. In M. J. Lambert (Ed.), Bergin and Garfield's handbook of psychotherapy and behavior change ( $5^{\text {th }}$ ed., pp. 139-193). New York: Wiley.

Lambert, M. J., Hansen, N. B., Umphress, V. J., Lunnen, K., Okiishi, J., Burlingame, G. M. et al., (1996). Administration and scoring manual for the Outcome Questionnaire (OQ 45.2). Wilmington, DL: American Professional Credentialing Services.

Lambert, M. J., Hansen, N. B., \& Finch, A. E. (2001). Patient-focused research: Using patient outcome data to enhance treatment effects. Journal of Consulting and Clinical Psychology, 69, 159-172.

Lambert, M. J., Whipple, J. L., Hawkins, E. J., Vermeersch, D. A., Nielsen, S. L., \& Smart, D. W. (2003). Is it time for clinicians to routinely track patient outcome?: A meta-analysis. Clinical Psychology: Science \& Practice, 10, 288-301.

Lambert, M. J., Whipple, J. L., Bishop, M. J., Vermeersch, D. A., Gray, G. V., \& Finch, A. E. (2002). Comparison of empirically derived and rationally derived methods for identifying clients at risk for treatment failure. Clinical Psychology and Psychotherapy, 9, 149-164. 
Lese, K. P., \& MacNair-Semands, R. R. (2000). The Therapeutic Factors Inventory: Development of a scale. Group, 24, 303-317.

Lueger, R. J., Howard, K. I., Martinovich, Z., Lutz, W., Anderson, E. E., \& Grissom, G. (2001). Assessing treatment progress of individual patients using expected treatment response models. Journal of Consulting and Clinical Psychology, 69, $150-158$.

MacKenzie, K. R. (1983). The clinical application of a group measure. In R. R. Dies \& K. R. MacKenzie (Eds.) Advances in group psychotherapy: Integrating research and practice (pp. 159-170). New York: International Universities Press.

MacKenzie, K. R., Dies, R. R., Coche, E., Rutan, J. S., \& Stone, W. N. (1987). An analysis of AGPA Institute groups. International Journal of Group Psychotherapy, 37(1), 55-74.

Marziali, E., Mumoe-Blum, H., \& McCleary, L. (1997). The contribution of group cohesion and group alliance to the outcome of group psychotherapy. International Journal of Group Psychotherapy, 47(4), 475-497.

McBride, L. (1995). Toward group process understanding: Leadership and group. climate. Unpublished doctoral dissertation, University of Missouri-Columbia.

McCallum, M., Piper, W. E., \& Ogrodniczuk, J. S., \& Joyce, A. S. (2002). Early Process and dropping out from short-term therapy for complicated grief. Group Dynamics, 6, 243-254.

Norcross, J. C. (2003). Empirically supported therapy relationships. In J. C. Norcross (Ed.), Psychotherapy relationships that work (pp.3-16). New York: Oxford University Press. 
Ogrodniczuk, J. S., \& Piper, W. E. (2003). The effect of group climate on outcome in two forms of short-term group therapy. Group Dynamics, 7, 64-76.

Ogrodiniezuk, J. (2005). CORE-R Battery: Assessment of group therapy outcomes. Group Circles, 3, 4-5.

Orlinksy, D. E., Grawe, K., \& Parks, B. K. (1994). Process and outcome in psychotherapy. In A. E. Bergin \& S. L. Garfield (Eds.), Handbook of psychotherapy and behavior change (lh ed., pp. 270-376). New York: Wiley.

Percevic, R., Lambert, M. J., \& Kordy, H. (2004). Computer-supported monitoring of patient treatment response. Journal of Clinical Psychology, 60, 285-299.

Persons, J. B., \& Burns, D. D. (1985). Mechanism of action of cognitive therapy: Relative contribution of technical and interpersonal intervention. Cognitive Therapy and Research, 9, 539-551.

Phipps, L. B., \& Zastowny, T. R. (1988). Leadership behavior, group climate and outcome in group psychotherapy: A study of outpatient psychotherapy groups. Group, 12, 157-171.

Piper, W. E., Joyce, A. S., Rosie, J. S., \& Azim, H. F. A. (1994). Psychological mindedness, work, and outcome in day treatment. International Journal of Group Psychotherapy. 44, 291-311.

Piper, W. E., Marrache, M., Lacroix, R., Richardson, A. M., \& Jones, B. D. (1983). Cohesion as a basic bond in groups. Human Relations, 36, 93-108.

Rosenberg, M. (1965). Society and the adolescent self image. Princeton, NJ: Princeton University Press.

Sexton, H. (1993). Exploring a psychotherapeutic change sequence: Relating process to 
intersessional and posttreatment outcome. Journal of Consulting and Clinical Psychology, 61(1), 128-136.

Slade, K., Lambert, M. J., Harmon, S C., Smart D W, and Bailey, R. (2008). Improving psychotherapy outcome: the use of immediate electronic feedback and revised clinical support tools. Journal of Clinical Psychology and Psychotherapy, 15(5), 287-303.

Sternburg, S., Trijburg, W. (2005). The relationship between therapeutic interventions and therapeutic outcome. (Unpublished)

Stokes, J. P. (1983). Toward an understanding of cohesion in personal change groups. International Journal of Group Psychotherapy, 33(4), 449-467.

Strauss, B., \& Burgmeier-Lohse, M. (1995). The "fit" between therapist and patient as a determinant of treatment outcome following inpatient group psychotherapy. Zeitschriftuer Psychosomatische Medizin und Psychoanalyse, 41, 127-140.

Trad, P. V. (1993). Using the prospective approach as an adjunct to established models of group psychotherapy. Group, 17(1), 43-60.

Tschuschke, V. \& Dies, R. R. (1994). Intensive analysis of therapeutic factors and outcome in long-term inpatient groups. International Journal of Group Psychotherapy, 44(2), 185-208.

Sepyta, J. Reimer, M., \& Bickman, L. (2005). Feedback to clinicians: theory research and practice. Journal of Clinical Psychology, 61, 145-153.

Whipple, J. L., Lambert, M. J., Vermeersch, D. A., Smart, D. W., Nielsen, S. L., \& 
Hawkins, E. J. (2003). Improving the effects of psychotherapy: The use of early identification of treatment failure and problem solving strategies in routine practice. Journal of Counseling Psychology, 58, 59-68.

Yalom (2005). The theory and practice of group psychotherapy (5th Ed.). New York: Basic Books. 


\section{Appendix 1: Measures Used}

\section{The Group Questionnaire}

Thank you for agreeing to complete the Group Questionnaire. The following questions ask about your personal experience in your therapy group. You will be presented with a question containing a blank space. For the bubbles on the left please place the words "group leaders" in the space and answer the question by filling in the bubble. For the bubbles on the right place the words "other group members" in the space and answer the question. Your answers may be different to the left and right sides of the same question. For example:

\section{Group Leaders}

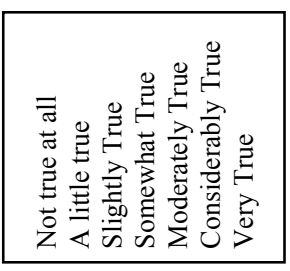

$\begin{array}{lllllllllllll}0 & 0 & 0 & 0 & 0 & 0 & 0\end{array}$
The
Other Group Members

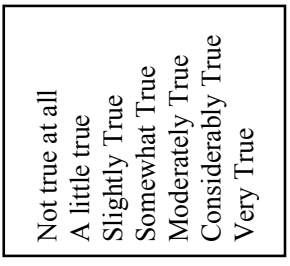

$\begin{array}{llllllllllll}0 & 0 & 0 & 0 & 0 & 0 & 0\end{array}$

\section{Group Leaders}

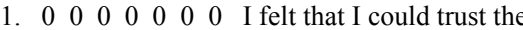

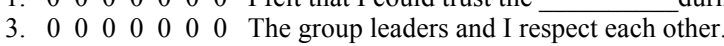

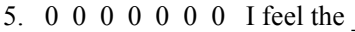
approve of.

7. $\begin{array}{lllllllll}0 & 0 & 0 & 0 & 0 & 0 & 0 & \text { The }\end{array}$

9. $\begin{array}{lllllllll}0 & 0 & 0 & 0 & 0 & 0 & 0 & \text { The }\end{array}$

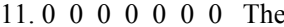

13. $0 \begin{array}{lllllll}0 & 0 & 0 & 0 & 0 & 0 & \text { The }\end{array}$ The

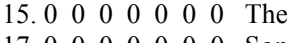
17.00000000000 Sometimes the 19. 00000000000

21.00000000000 care about me even when I do things that they do not were friendly and warm toward me. and I agree about the things I will need to do in therapy. and I agree on what is important to work on. and I have established a good understanding of the kind of would be good for me. and I are working together toward mutually agreed upon goals. did not always seem to care about me. did not always understand the way I felt inside.

\section{Other Group Members}

2. $\begin{array}{lllllll}0 & 0 & 0 & 0 & 0 & 0 & 0\end{array}$

4. $\begin{array}{lllllll}0 & 0 & 0 & 0 & 0 & 0 & 0\end{array}$

6. $\begin{array}{llllllll}0 & 0 & 0 & 0 & 0 & 0 & 0\end{array}$

8. $\begin{array}{llllllll}0 & 0 & 0 & 0 & 0 & 0 & 0\end{array}$

10. $0 \begin{array}{lllllll}0 & 0 & 0 & 0 & 0 & 0 & 0\end{array}$

12. $0 \begin{array}{lllllll}0 & 0 & 0 & 0 & 0 & 0 & 0\end{array}$

14. $\begin{array}{lllllll}0 & 0 & 0 & 0 & 0 & 0 & 0\end{array}$

16. $\begin{array}{lllllll}0 & 0 & 0 & 0 & 0 & 0 & 0\end{array}$

18. $0 \begin{array}{lllllll}0 & 0 & 0 & 0 & 0 & 0 & 0\end{array}$

20. $0 \begin{array}{llllllll}0 & 0 & 0 & 0 & 0 & 0 & 0\end{array}$

22. $0 \begin{array}{lllllll}0 & 0 & 0 & 0 & 0 & 0 & 0\end{array}$

These questions ask about your experience with your group in general. Please respond by filling in the bubble to the right of the question.

\section{The Group in General}

23. There was friction and anger between the members.

$\begin{array}{lllllll}0 & 0 & 0 & 0 & 0 & 0 & 0\end{array}$

24. The members were distant and withdrawn from each other.

$\begin{array}{lllllllllllll}0 & 0 & 0 & 0 & 0 & 0 & 0\end{array}$

25. There was tension and anxiety between the members.

26. The members liked and cared about each other.

$\begin{array}{lllllll}0 & 0 & 0 & 0 & 0 & 0 & 0\end{array}$

$\begin{array}{llllllllllllll}0 & 0 & 0 & 0 & 0 & 0 & 0\end{array}$

27. The members felt what was happening was important and there was a sense of participation.

$\begin{array}{lllllllllll}0 & 0 & 0 & 0 & 0 & 0 & 0\end{array}$

28. We cooperate and work together in group.

$\begin{array}{lllllllllllll}0 & 0 & 0 & 0 & 0 & 0 & 0\end{array}$

29. Even though we have differences, our group feels secure to me.

$\begin{array}{llllllllll}0 & 0 & 0 & 0 & 0 & 0 & 0\end{array}$

30. The group members accept one another.

$0 \begin{array}{lllllllllll}0 & 0 & 0 & 0 & 0 & 0 & 0\end{array}$ 


\section{GROUP PSYCHOTHERAPY INTERVENTION RATING SCALE (GPIRS)}

Intervention did not occur $=0$

Intervention was ambiguous, unclear $=1$

Intervention was performed with average Clarity $=2$

Intervention was performed with lucid clarity $=3$

Intervention performed in a precise and transparent manner $=4$

\begin{tabular}{|c|c|c|c|c|c|c|}
\hline \multicolumn{7}{|c|}{$\begin{array}{c}\text { Group Structuring (may be applied in any group session, at any time during a session, but probably } \\
\text { more so in early sessions) }\end{array}$} \\
\hline \multirow{3}{*}{$\begin{array}{l}\text { Setting treatment } \\
\text { expectation }\end{array}$} & 1. Set group agendas (such as discussion topics or group activities) & 0 & 1 & 2 & 3 & 4 \\
\hline & 2. Described rationale underlying treatment & 0 & 1 & 2 & 3 & 4 \\
\hline & 3. Identified and discussed fears/concerns regarding self disclosure & 0 & 1 & 2 & 3 & 4 \\
\hline \multirow{2}{*}{$\begin{array}{l}\text { Establishing group } \\
\text { procedures }\end{array}$} & $\begin{array}{l}\text { 4. Discussed group rules (such as time, attendance, absences, tardiness, } \\
\text { confidentiality, participation) }\end{array}$ & 0 & 1 & 2 & 3 & 4 \\
\hline & 5. Structured exercises that focus on emotional expression and exchange & 0 & 1 & 2 & 3 & 4 \\
\hline \multirow[t]{2}{*}{ Role preparation } & 6. Discussed member roles and responsibility. & 0 & 1 & 2 & 3 & 4 \\
\hline & 7. Discussed leader roles and responsibility. & 0 & 1 & 2 & 3 & 4 \\
\hline
\end{tabular}




\section{Verbal interaction}

\section{Goal of intervention Skills of the therapist:}

\section{Verbal style} and interaction

8. Modeled giving personal information in the "here and now"

9. Modeled appropriate member-member behavior

10. Modeled appropriate self disclosure

11. Modeled appropriate feeling disclosure

\section{Therapist towards the Group:}

\begin{tabular}{lllllll} 
12. Maintained moderate control & 0 & 1 & 2 & 3 & 4 \\
\hline 13. Facilitated appropriate member-member interaction & 0 & 1 & 2 & 3 & 4 \\
\hline
\end{tabular}

Self disclosure

\section{Skills of the therapist:}

14. Encouraged self disclosure without "forcing it". $\quad 0 \quad \begin{array}{lllll}1 & 2 & 3 & 4\end{array}$

15. Encouraged self disclosure relevant to the current group agenda. $\quad \begin{array}{llllll}0 & 1 & 2 & 3 & 4\end{array}$

16. Helped members understand that disclosed issues achieve more resolution than undisclosed issues

$\begin{array}{lllll}0 & 1 & 2 & 3 & 4\end{array}$

\section{Therapist towards the Group:}

17. Encouraged here-and-now vs. story-telling disclosure

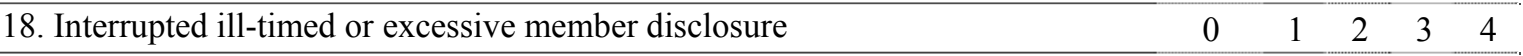

19. Elicited member-member feeling disclosure (versus informational disclosures) $\quad \begin{array}{llllll}0 & 1 & 2 & 3 & 4\end{array}$

20. Leader shared relevant personal experience from outside of therapy (without being judgmental or overly-intellectual)

$\begin{array}{lllll}0 & 1 & 2 & 3 & 4\end{array}$

Feedback

\section{Skills of the therapist:}

21. Reframed injurious feedback (interrupting, if necessary)

22. Restated corrective feedback by member

$\begin{array}{lllll}0 & 1 & 2 & 3 & 4\end{array}$

23. Used consensus to reinforce feedback (toward therapist or group member)

24. Balanced positive and corrective leader-to-member feedback

$\begin{array}{lllll}0 & 1 & 2 & 3 & 4 \\ 0 & 1 & 2 & 3 & 4\end{array}$

Therapist towards the Group:

25. Encouraged positive feedback

26. Gave structured feedback exercise

27. Helped balance positive and corrective member-to-member feedback

28. Therapist helped members apply in-group feedback to out-of-group situations.

$\begin{array}{lllll}0 & 1 & 2 & 3 & 4 \\ 0 & 1 & 2 & 3 & 4 \\ 0 & 1 & 2 & 3 & 4 \\ 0 & 1 & 2 & 3 & 4\end{array}$




\section{Creating and maintaining a therapeutic emotional climate}

\begin{tabular}{|c|c|c|c|c|c|c|}
\hline \multirow{3}{*}{$\begin{array}{l}\text { Goal of intervention } \\
\text { Leader contribution }\end{array}$} & \multicolumn{6}{|l|}{ Skills of the therapist: } \\
\hline & 29. Maintained balance in expressions of emotional support and confrontation & 0 & 1 & 2 & 3 & 4 \\
\hline & 30. Showed understanding of the members and their concerns & 0 & 1 & 2 & 3 & 4 \\
\hline & $\begin{array}{l}\text { 31. Refrained from conveying personal feelings of hostility and anger in } \\
\text { response to negative member behavior (If there was no substantial negative } \\
\text { behavior, mark 0). }\end{array}$ & 0 & 1 & 2 & 3 & 4 \\
\hline & 32. Leader was not defensive when interventions failed. & 0 & 1 & 2 & 3 & 4 \\
\hline & $\begin{array}{l}\text { 33. Leader was not defensive when confronted by a member (If therapist was not } \\
\text { confronted by a member, mark } 0 \text { ). }\end{array}$ & 0 & 1 & 2 & 3 & 4 \\
\hline & 34. Maintained an active engagement with the group and its work. & 0 & 1 & 2 & 3 & 4 \\
\hline & 35. Used nonjudgmental language with members. & 0 & 1 & 2 & 3 & 4 \\
\hline \multirow{12}{*}{ Member contribution } & Therapist towards the Group: & & & & & \\
\hline & 36. Modeled expressions of open and genuine warmth & 0 & 1 & 2 & 3 & 4 \\
\hline & 37. Encouraged active emotional engagement between group members & 0 & 1 & 2 & 3 & 4 \\
\hline & 38. Fostered a climate of both support and challenge & 0 & 1 & 2 & 3 & 4 \\
\hline & 39. Responded at an emotionally empathic level & 0 & 1 & 2 & 3 & 4 \\
\hline & 40. Developed and/or facilitated relationships with and among group members & 0 & 1 & 2 & 3 & 4 \\
\hline & $\begin{array}{l}\text { 41. Helped members recognize why they feel a certain way (identifying } \\
\text { underlying concerns or motives) }\end{array}$ & 0 & 1 & 2 & 3 & 4 \\
\hline & \multicolumn{6}{|l|}{ Skills of the therapist: } \\
\hline & $\begin{array}{l}\text { 42. Prevented or stopped attacking and judgmental expressions between members } \\
\text { (If no opportunity for this intervention occurred, mark } 0 \text { ) }\end{array}$ & 0 & 1 & 2 & 3 & 4 \\
\hline & 43. Assisted members in describing their emotions & 0 & 1 & 2 & 3 & 4 \\
\hline & 44. Recognized and responded to the meaning of groups members' comments & 0 & 1 & 2 & 3 & 4 \\
\hline & $\begin{array}{l}\text { 45. Prevented situations in which members felt discounted, misunderstood, } \\
\text { attacked, or disconnected (If no situation-occurred, mark } 0 \text { ) }\end{array}$ & 0 & 1 & 2 & 3 & 4 \\
\hline
\end{tabular}




\section{Therapist towards the Group:}

46. Involved members in describing and resolving conflict (instead of avoiding conflict)

$\begin{array}{llll}0 & 1 & 2 & 3\end{array}$

47. Elicited verbal expressions of support among group member

$\begin{array}{lllll}0 & 1 & 2 & 3 & 4\end{array}$

48. Encouraged members to respond to other members' emotional expression

$\begin{array}{lll}2 & 3 & 4\end{array}$ 


\section{Appendix II: Prediction and Feedback Forms}

\section{OQ-45 Prediction Form}

Group Member: D. Stevenson

Group: Depressed Puerto Rican Somnambulism Support Group

Group Leaders: A.B., G.A.

Session: $7 / 21 / 79$; session 3

The following form asks you to predict the outcome of treatment for one of your group members. In making this prediction, consider your interactions with the client, your experience with him/her, and based on your own clinical judgment and past experience, predict his/her level of improvement as measured by the OQ-45 at the termination of group therapy (circle the predicted outcome):

\section{Reliably Improved}

1
No Reliable Change

2
Reliably Worse

3 


\section{Group Questionnaire Prediction Form}

Group Member: B. Hansen

Group: Depressed Puerto Rican Somnambulism Support Group

Group Leaders: C.C., D.T.

Session: $7 / 21 / 79$; session 3

The following form asks you to predict one of your group member's perception of the therapeutic relationship in your group. In making this prediction, consider your interactions with the client, your client's behavior and participation in your group, and based on your own clinical judgment and past experience, rate the level of accuracy from 1 (not true at all) to 7 (very true) of the following statements at the end of the most recent session of group therapy:

Rate the truthfulness of the following statements in regards to the group member listed above on a scale from 1 (Not true at all) to 7 (very true):

Positive Bonding Relationship: The member feels a strong emotional connection or attachment to the other members of the group, including the therapist, and with the group-as-a-whole.

Not True at All

12

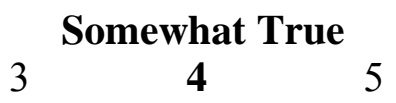

6

Very True

$6 \quad 7$

Positive Working Relationship: the member feels a sense of collaborative engagement in their therapeutic work with the other members, the therapist, and the group-as-a-whole in progressing towards treatment goals.

Not True at All

12

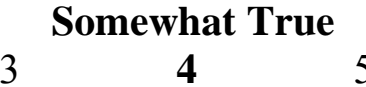

Very True

7

Negative Relationship: The member perceives that there is a high level of conflict, tension, and lack of empathy and understanding within the group.

Not True at All

1
2

$3 \begin{gathered}\text { Somewhat True } \\ 4\end{gathered}$

Very True 


\title{
GROUP PSYCHOTHERAPY INTERVENTION RATING SCALE (GPIRS) PREDICTION FORM
}

\author{
Intervention did not occur $=0$ \\ Ambiguous, unclear $=1$ \\ Average Clarity $=2$ \\ Lucid $=3$ \\ Precise and Transparent $=4$
}

Instructions: After reading over the interventions in each domain (Group Structuring, Verbal Interaction, Creating and Maintaining a Therapeutic Emotional Climate) list the number of total interventions you used from the list under each domain in the space provided. Below this, give yourself an overall rating on the clarity of delivery of interventions used on a scale from 1 (ambiguous, unclear) to 4 (precise and transparent). As you do so, think back on the interventions used during the session and ask yourself from a strict behavioral perspective, if an outside rater were to rate the purpose of your interventions, how clear would your specific intention in delivering the intervention be?

If you wish, you may fill out ratings for yourself for each intervention, but this is optional.

Example: Below are examples representing possible ratings from 1 (ambiguous, unclear) to 4 (precise and transparent) for Item 4 from the GPIRS (Discussed group rules such as time, attendance, absences, tardiness, confidentiality, participation)

Group Leader: "It looks like we might have some late arrivals to our group today." (Ambiguous, unclear =1)

Group Leader: “As we've discussed, we need to try to be on time for every group meeting." (Average Clarity= 2)

Group Leader: "We all agree that showing up to group on time is important for the group to function well. Please try to be on time next week." (Lucid =3)

Group Leader: "As we have discussed, we will start the group at 6:30 whether people are here or not. In order to demonstrate your commitment to your work in group, you need to arrive on time. Otherwise, we will start without you." (Precise and Transparent=4) 


\begin{tabular}{|c|c|c|c|c|c|c|}
\hline \multicolumn{2}{|r|}{ Group Structuring } & & & & & \\
\hline \multirow{3}{*}{$\begin{array}{l}\text { Setting treatment } \\
\text { expectation }\end{array}$} & 1. Set group agendas (such as discussion topics or group activities) & 0 & 1 & 2 & 3 & 4 \\
\hline & 2. Described rationale underlying treatment & 0 & 1 & 2 & 3 & 4 \\
\hline & 3. Identified and discussed fears/concerns regarding self disclosure & 0 & 1 & 2 & 3 & 4 \\
\hline \multirow[t]{2}{*}{$\begin{array}{l}\text { Establishing group } \\
\text { procedures }\end{array}$} & $\begin{array}{l}\text { 4. Discussed group rules (such as time, attendance, absences, tardiness, confidentiality, } \\
\text { participation) }\end{array}$ & 0 & 1 & 2 & 3 & 4 \\
\hline & 5. Structured exercises that focus on emotional expression and exchange & 0 & 1 & 2 & 3 & 4 \\
\hline \multirow{2}{*}{ Role preparation } & 6. Discussed member roles and responsibility. & 0 & 1 & 2 & 3 & 4 \\
\hline & 7. Discussed leader roles and responsibility. & 0 & 1 & 2 & 3 & 4 \\
\hline
\end{tabular}

Of the interventions listed above, how many were used during the session today?

Rate yourself on the overall clarity with which you performed these interventions: 


\section{Verbal interaction}

\section{Goal of intervention Skills of the therapist:}

Verbal style and interaction

8. Modeled giving personal information in the "here and now"

9. Modeled appropriate member-member behavior

10. Modeled appropriate self disclosure

11. Modeled appropriate feeling disclosure

\section{Therapist towards the Group:}

\begin{tabular}{llllll} 
12. Maintained moderate control & 0 & 1 & 2 & 3 & 4 \\
\hline 13. Facilitated appropriate member-member interaction & 0 & 1 & 2 & 3 & 4
\end{tabular}

Self disclosure

\section{Skills of the therapist:}

14. Encouraged self disclosure without "forcing it". $\quad \begin{array}{llllll}0 & 1 & 2 & 3 & 4\end{array}$

15. Encouraged self disclosure relevant to the current group agenda. $\quad 0 \quad 0 \quad 1 \quad 2 \quad 3 \quad 4$

16. Helped members understand that disclosed issues achieve more resolution than undisclosed issues

$\begin{array}{lllll}0 & 1 & 2 & 3 & 4 \\ 0 & 1 & 2 & 3 & 4\end{array}$

\section{Therapist towards the Group:}

17. Encouraged here-and-now vs. story-telling disclosure

$\begin{array}{lllll}0 & 1 & 2 & 3 & 4\end{array}$

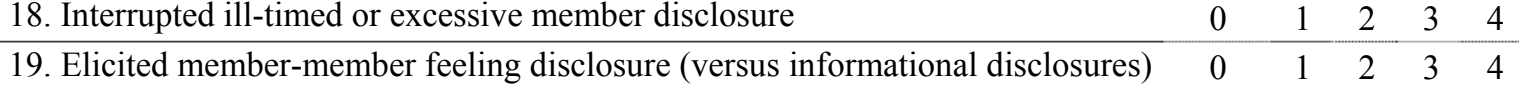

20. Leader shared relevant personal experience from outside of therapy (without $\quad \begin{array}{lllllll}0 & 1 & 2 & 3 & 4\end{array}$

being judgmental or overly-intellectual)

\section{Feedback}

\section{Skills of the therapist:}

21. Reframed injurious feedback (interrupting, if necessary)

22. Restated corrective feedback by member

\begin{tabular}{lllll}
0 & 1 & 2 & 3 & 4 \\
\hline
\end{tabular}

23. Used consensus to reinforce feedback (toward therapist or group member)

24. Balanced positive and corrective leader-to-member feedback

$\begin{array}{lllll}0 & 1 & 2 & 3 & 4\end{array}$

Therapist towards the Group:

25. Encouraged positive feedback

26. Gave structured feedback exercise

27. Helped balance positive and corrective member-to-member feedback

28. Therapist helped members apply in-group feedback to out-of-group situations.

\begin{tabular}{lrrrrr} 
25. Encouraged positive feedback & 0 & 1 & 2 & 3 & 4 \\
\hline 26. Gave structured feedback exercise & 0 & 1 & 2 & 3 & 4 \\
\hline 27. Helped balance positive and corrective member-to-member feedback & 0 & 1 & 2 & 3 & 4 \\
\hline 28. Therapist helped members apply in-group feedback to out-of-group situations. & 0 & 1 & 2 & 3 & 4 \\
\hline
\end{tabular}




\section{Creating and maintaining a therapeutic emotional climate}

\begin{tabular}{|c|c|c|c|c|c|c|}
\hline \multirow{2}{*}{$\begin{array}{l}\text { Goal of intervention } \\
\text { Leader contribution }\end{array}$} & \multicolumn{6}{|l|}{ Skills of the therapist: } \\
\hline & 29. Maintained balance in expressions of emotional support and confrontation & 0 & 1 & 2 & 3 & 4 \\
\hline & 30. Showed understanding of the members and their concerns & 0 & 1 & 2 & 3 & 4 \\
\hline & $\begin{array}{l}\text { 31. Refrained from conveying personal feelings of hostility and anger in } \\
\text { response to negative member behavior (If there was no substantial negative } \\
\text { behavior, mark } 0 \text { ). }\end{array}$ & 0 & 1 & 2 & 3 & 4 \\
\hline & 32. Leader was not defensive when interventions failed. & 0 & 1 & 2 & 3 & 4 \\
\hline & $\begin{array}{l}\text { 33. Leader was not defensive when confronted by a member (If therapist was not } \\
\text { confronted by a member, mark } 0 \text { ). }\end{array}$ & 0 & 1 & 2 & 3 & 4 \\
\hline & 34. Maintained an active engagement with the group and its work. & 0 & 1 & 2 & 3 & 4 \\
\hline & 35. Used nonjudgmental language with members. & 0 & 1 & 2 & 3 & 4 \\
\hline & \multicolumn{6}{|l|}{ Therapist towards the Group: } \\
\hline & 36. Modeled expressions of open and genuine warmth & 0 & 1 & 2 & 3 & 4 \\
\hline & 37. Encouraged active emotional engagement between group members & 0 & 1 & 2 & 3 & 4 \\
\hline & 38. Fostered a climate of both support and challenge & 0 & 1 & 2 & 3 & 4 \\
\hline & 39. Responded at an emotionally empathic level & 0 & 1 & 2 & 3 & 4 \\
\hline & 40. Developed and/or facilitated relationships with and among group members & 0 & 1 & 2 & 3 & 4 \\
\hline & $\begin{array}{l}\text { 41. Helped members recognize why they feel a certain way (identifying } \\
\text { underlying concerns or motives) }\end{array}$ & 0 & 1 & 2 & 3 & 4 \\
\hline
\end{tabular}


Member contribution Skills of the therapist:

42. Prevented or stopped attacking and judgmental expressions between members

(If no opportunity for this intervention occurred, mark 0 )

43. Assisted members in describing their emotions

$\begin{array}{lllll}0 & 1 & 2 & 3 & 4\end{array}$

44. Recognized and responded to the meaning of groups members' comments

45. Prevented situations in which members felt discounted, misunderstood,

$\begin{array}{lll}2 & 3 & 4\end{array}$

attacked, or disconnected (If no situation occurred, mark 0)

\section{Therapist towards the Group:}

46. Involved members in describing and resolving conflict (instead of avoiding conflict)

47. Elicited verbal expressions of support among group members

48. Encouraged members to respond to other members' emotional expression (such as acceptance, belonging, empathy)

$\begin{array}{lllll}0 & 1 & 2 & 3 & 4\end{array}$

$\begin{array}{lllll}0 & 1 & 2 & 3 & 4\end{array}$

Of the interventions listed above, how many were used during the session today? 


\section{SESSION THREE - GROUP THERAPY FEEDBACK SHEET}

Group Name: Somnambulism

Leader 1: J. Edgar Hoover
Date: $1 / 28 / 2009$

Leader 2: .

\section{Group Questionnaire - Results}

Participants' $T$ Scores are collated in the table below according to the following descriptors:

Positive Bonding Relationship (Pos Bond): the indiridual member's connection or attachment to the other members of the group, including the therapist, and the group-as-a-trhole.

Above Average $(T>60)$ : Strongly bonded to the group, likely feels emotionally connected by the therapist and other group members.

Average $(60>\mathrm{T}>40)$ : Feels an average degree of connectedness to the group and generally feels understood and empathized with by his/her fellow group members and group leader(s).

Below Average $(T<40)$ : Does not feel connected with or understood by the group. The member likely does not feel strongly attached or supported by the relationship he/she experiences with the group members and group leader(s).

Positive Working Relationship (Pos Work): the individual member's collaborative engagement in therapeutic work with the other members, the therapist, and the group-as-a-whole for the purpose of progressing towards treatment goals.

Above Average $(T>60)$ : Enjoys a potrerful sense of engagement and involvement with group members and leader(s) in the primary tasks of their therapeutic work in the group. The member feels that the group collaborates well in working towards treatment goals.

Average $(60>\mathrm{T}>40)$ : The member feels an average level of engagement and intolvement in the therapeutic work of the group. While the member may not always feel a sense of collaboration with other members and leader(s) in working towards agreed-upon treatment goals, the group is seen as being generally effective in working together.

Below Average $(T<40)$ : The member does not feel a sense of collaborative engagement with the group. The member likely feels as if other members and group leader(s) do not assist the member in working towards treatment goals.

Negative Relationship (Neg Rel); aspects of the group process that may adversely affect member attachments or impede the therapeutic work.

Above Average $(T>60)$ : The client feels a strong sense of hostility and conflict in the group.

Average $(60>\mathrm{T}>40)$ : The client feels an average level of hostility and conflict in the group.

Below Average $(\mathrm{T}<40)$ : The client experiences lower than average levels of hostility and conflict in the group.

\begin{tabular}{|c|c|c|c|}
\hline Participant & Pos Bond & Pos Work & Neg Rel \\
\hline T.R. & 42 & 37 & 42 \\
\hline M.M. & 59 & 74 & 35 \\
\hline J.S. & 56 & 50 & 48 \\
\hline O.P. & 52 & 46 & 61 \\
\hline K.M. & 58 & 53 & 48 \\
\hline G.O. & & & \\
\hline P.S. & 52 & 45 & 53 \\
\hline T.L. & 51 & 47 & 57 \\
\hline
\end{tabular}

\begin{tabular}{|c|c|c|c|}
\hline Participant & Pos Bond & Pos Work & Neg Rel \\
\hline$\cdot$ &. &. & \\
\hline$\cdot$ &. &. & \\
\hline. &. &. & \\
\hline. &. &. & \\
\hline. &. &. & \\
\hline. &. &. & \\
\hline. &. & & \\
\hline. &. & & \\
\hline
\end{tabular}




\section{GPIRS Feedback Form}

Group Name: Depressed Puerto Rican Somnambulism Support Group

Group Leader(s): D.S., C.B

Session: $7 / 21 / 79$; session 3

\section{GPIRS scores}

Group Structuring Section:

-Percent of interventions used: $71.42 \%$

-Clarity of delivery in interventions used: 3.2 Lucid to Precise and Transparent

Interventions used-

1. Set group agendas (such as discussion topics or group activities)

2. Described rationale underlying treatment

3. Identified and discussed fears/concerns regarding self disclosure

4. Discussed group rules (such as time, attendance, absences, tardiness, confidentiality, participation)

5. Structured exercises that focus on emotional expression and exchange

Interventions not used-

6. Discussed member roles and responsibility.

7. Discussed leader roles and responsibility.

Verbal Interaction Section:

- Percent of interventions used: $76.19 \%$

- Clarity of delivery in interventions used: 2.33 Average Clarity to Lucid

Interventions used-

8. Modeled giving personal information in the "here and now"

9. Modeled appropriate member-member behavior

10. Modeled appropriate self disclosure

11. Modeled appropriate feeling disclosure

12. Maintained moderate control

13. Facilitated appropriate member-member interaction

14. Encouraged self disclosure without "forcing it".

15. Encouraged self disclosure relevant to the current group agenda.

17. Encouraged here-and-now vs. story-telling disclosure

19. Elicited member-member feeling disclosure (versus informational disclosures)

23. Used consensus to reinforce feedback (toward therapist or group member)

24. Balanced positive and corrective leader-to-member feedback

25. Encouraged positive feedback

26. Gave structured feedback exercise

27. Helped balance positive and corrective member-to-member feedback

28. Therapist helped members apply in-group feedback to out-of-group situations 
Interventions not used-

16. Helped members understand that disclosed issues achieve more resolution than undisclosed issues

18. Interrupted ill-timed or excessive member disclosure

20. Leader shared relevant personal experience from outside of therapy (without being judgmental or overly-intellectual)

21. Reframed injurious feedback (interrupting, if necessary)

22. Restated corrective feedback by member

Maintenance of Therapeutic Emotional Climate Section:

- Percent of interventions used: $90.00 \%$

- Clarity of delivery in interventions used: 2.69 Average Clarity to Lucid

Interventions used-

29. Maintained balance in expressions of emotional support and confrontation

30. Showed understanding of the members and their concerns

32. Leader was not defensive when interventions failed.

34. Maintained an active engagement with the group and its work.

35. Used nonjudgmental language with members.

36. Modeled expressions of open and genuine warmth

37. Encouraged active emotional engagement between group members

38. Fostered a climate of both support and challenge

39. Responded at an emotionally empathic level

40. Developed and/or facilitated relationships with and among group members

41. Helped members recognize why they feel a certain way (identifying underlying concerns or motives)

43. Assisted members in describing their emotions

44. Recognized and responded to the meaning of groups members' comments

45. Prevented situations in which members felt discounted, misunderstood, attacked, or disconnected (If no situation occurred, mark 0)

46. Involved members in describing and resolving conflict (instead of avoiding conflict 47. Elicited verbal expressions of support among group members

48. Encouraged members to respond to other members' emotional expression (such as acceptance, belonging, empathy)

Interventions not used-

31. Refrained from conveying personal feelings of hostility and anger in response to negative member behavior (If there was no substantial negative behavior, mark 0 ). 33. Leader was not defensive when confronted by a member (If therapist was not confronted by a member, mark 0 ).

42. Prevented or stopped attacking and judgmental expressions between members (If no opportunity for this intervention occurred, mark 0 )

\section{Overall GPIRS Scores}

-Percent of interventions used: $81.25 \%$

- Clarity of delivery in interventions used: 2.85 Average Clarity to Lucid 


\section{OQ-45/S-OQ Feedback Sheet}

SOQ_ClinicianReport

Page 1 of 1

\begin{tabular}{ll||}
\hline Name: & C-SOQ, JUSTIN ID: MRN01239 \\
Session Date: & $12 / 27 / 2006 \quad$ Session: 6 \\
Clinician: & Clinician, Adam Clinic: \\
Diagnosis: & Unknown Diagnosis \\
Completed By: & Self \\
Instrument: & SOQ ${ }^{\circledR}-2.0$ \\
\hline \hline
\end{tabular}

Most Recent Critical Item Status:

7. Suicide - I have thoughts of ending my Sometimes life.

11. Substance Abuse - I use alcohol or a Sometimes drug to get going in the morning.

20. Substance Abuse - People criticize my Sometimes drinking (or drug use).

24. Substance Abuse - I have trouble at Sometimes work/school or other daily activities because of drinking or drug use.

31. Hallucinations - I see or hear things thatFrequently other people don't.

32. Mania - I can't stop thinking, moving, or Sometimes doing things.

43. Morbidity - I think I am really ill. Never

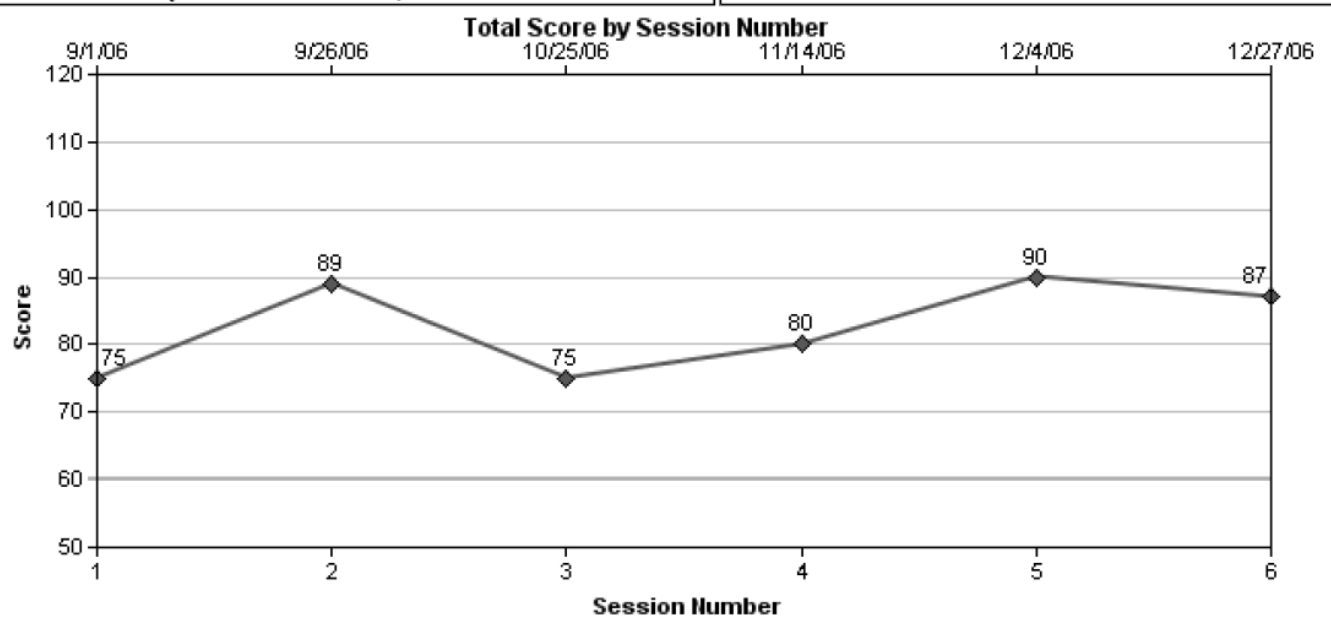

